\title{
Gestión urbanística integral del suelo: plusvalías y servicios ambientales
}

\author{
Jorge Agudo González \\ Profesor Titular de Derecho Administrativo \\ Universidad Autónoma de Madrid \\ jorge.agudo@uam.es
}

\begin{abstract}
Resumen
Nuestro Derecho urbanístico ha dedicado enormes esfuerzos en desarrollar mecanismos jurídicos que permiten explicar tanto la generación de plusvalías, como su concesión y distribución equitativa entre los propietarios de suelo urbanizable. Éste es el resultado de configurar nuestro urbanismo como un modelo de "urbanismo rentable" basado en la creación de ciudad. Esta cuestión ha influido en el tratamiento jurídico-urbanístico dedicado a los suelos no urbanizables, centrado en su protección y en la negación de contenidos urbanísticos rentables. Sin embargo, este planteamiento no ha considerado adecuadamente que los suelos rústicos con valores merecedores de protección prestan servicios ambientales a toda la comunidad sin contraprestación alguna para sus propietarios. Para corregir esa dinámica, el ordenamiento ha previsto mecanismos jurídicos diversos cuya finalidad es la colectivización de las cargas que supone la prestación de servicios ambientales. No obstante, estos instrumentos sólo contribuyen al costeamiento de la ejecución de las obligaciones inherentes a la función social de la propiedad, pero no la valorizan. Esos mecanismos han sido superados por la aplicación renovada de técnicas urbanísticas tradicionales que permiten integrar al suelo no urbanizable que presta servicios ambientales en el marco de una ordenación y gestión urbanística integral que compensa la prestación de esos servicios.
\end{abstract}

Palabras clave Servicios ambientales, plusvalías, equidistribución, gestión urbanística integral, suelo no urbanizable.

\section{Integrated urban management: economic gains and environmental services}

\begin{abstract}
Spanish urban Law has dedicated important efforts to justify and to develop legal mechanisms that allow explaining both the generation of capital gains, and its granting and equitable distribution among land owners. This is the result of determining our town planning as a model of 'profitable' urbanism based on the 'creation' of city. The prominence of this question has influenced in the legal-urban processing dedicated to rural lands, concentrating on its protection and in the negation of any profitable urban content. However, this approach has not properly considered that rural lands provide environmental services to all the community without any compensation for its owners. To avoid that pernicious dynamic, the legal system has foreseen legal mechanisms whose aim is the redistribution of duties that environmental services provision implies. Nonetheless, these instruments just contribute to finance the execution of the inherent obligations of property; in any case, those instruments do not value the property itself. However, these traditional mechanisms have been overcome for the renewed application of traditional urban techniques. They allow integrating to the rural lands that provide environmental services within the framework of an integrated urban management which compensate to the land owners.
\end{abstract}

Key words

Environmental services, economic gains, equitable distribution, integrated urban management, rural lands. 


\section{PLUSVALÍAS Y SERVICIOS AMBIENTALES}

Los importantes beneficios derivados de la generación de plusvalías vinculadas a la actividad de ejecución de la obra-servicio público de urbanización imputable a los propietarios de suelo urbanizable, explican en buena medida por qué nuestro sistema urbanístico se ha caracterizado como un modelo centrado en la oferta de suelo. En la lógica de la concepción estatutaria del derecho de propiedad, el aprovechamiento urbanístico es una facultad graciable otorgada por el planificador', ligada a su discrecionalidad clasificatoria; en consecuencia, sólo mediante la generación de suelo transformable (suelo urbanizable) los propietarios de suelo obtienen una rentabilidad de la que carece el suelo en situación básica rural [por utilizar la terminología del vigente Decreto Legislativo 2/2008, de 20 de junio (TRLS de 2008)]. Precisamente por ese motivo, nuestro Derecho urbanístico ha dedicado enormes esfuerzos conceptuales y técnicos a justificar y desarrollar mecanismos jurídicos que permitan explicar tanto la generación de esas plusvalías, como su concesión y distribución equitativa entre los propietarios de suelo urbanizable.

Este planteamiento, que ha dominado todo nuestro urbanismo, es el resultado de la aceptación de un modelo de "urbanismo rentable" basado en la creación de ciudad $^{2}$. Un urbanismo, en definitiva, que confiere el monopolio de los aprovechamientos urbanísticos a una clase de suelo (lo que genera dudas razonables, desde el punto de vista del contenido rentable del derecho, acerca del tratamiento jurídico otorgado a los suelos no beneficiados con tales aprovechamientos 3 ) y selectivo

1 Parejo Alfonso, L. (1995): “La propiedad urbana”, en Barnés Vázquez, J. (coord.), Propiedad, expropiación y responsabilidad. La garantía indemnizatoria en el Derecho europeo y comparado, Madrid, Civitas, pp. 234 y 236, señala que la legislación de suelo “excluye el ‘aprovechamiento urbanístico' tanto de los bienes o cosas a que se refiere al tratar, con carácter general, de la propiedad, como, por tanto, del contenido propio o intrínseco de ésta en cuanto derecho". A ello añade que "la Ley configura el referido aprovechamiento como creación de la ordenación urbanística y, principalmente, del planeamiento, es decir, como creación del poder público".

2 No es casualidad que la STC 61/1997 (FJ 7) definiera el objeto del urbanismo precisamente por referencia a ese fenómeno: “... el urbanismo, como sector material susceptible de atribución competencial, alude a la disciplina jurídica del hecho social o colectivo de los asentamientos de población en el espacio físico, lo que, en el plano jurídico, se traduce en la 'ordenación urbanística', como objeto normativo de las Leyes urbanísticas (recogida en la primera Ley del Suelo de 1956, art. $1^{\circ}{ }^{\circ}$ ). Sin propósito definitorio, el contenido del urbanismo se traduce en concretas potestades (en cuanto atribuidas o controladas por Entes públicos), tales como las referidas al planeamiento, la gestión o ejecución de instrumentos planificadores y la intervención administrativa en las facultades dominicales sobre el uso del suelo y edificación, a cuyo servicio se arbitran técnicas jurídicas concretas; a lo que ha de añadirse la determinación, en lo pertinente, del régimen jurídico del suelo en tanto que soporte de la actividad transformadora que implica la urbanización y edificación. El contenido que acaba de enunciarse se traduce en la fijación de lo que pudiéramos llamar políticas de ordenación de la ciudad, en tanto en cuanto mediante ellas se viene a determinar el cómo, cuándo y dónde deben surgir o desarrollarse los asentamientos humanos, y a cuyo servicio se disponen las técnicas e instrumentos urbanísticos precisos para lograr tal objetivo".

3 La corrección de la desigualdad en estos supuestos ha sido reclamada por autores como Parada Vázquez, R. (1988): Derecho Administrativo. Bienes públicos y urbanismo, Madrid, Marcial Pons, pp. 284 y ss., o Lobato Gómez, J. M. (1989): Propiedad privada del suelo y derecho a edificar, Madrid, Montecorvo, p. 602. Sin embargo, desde la visión mayoritaria de la doctrina, Fernández Rodríguez, T. R. (1991): Manual de 
en el reconocimiento de aprovechamientos urbanísticos (lo que puede dar lugar a tratamientos discriminatorios que afecten a los propietarios no beneficiados por la reclasificación de suelo, a pesar de hallarse en circunstancias similares a los favorecidos por la misma). En definitiva, un modelo urbanístico ajustado a un régimen jurídico de la propiedad inmobiliaria variable fundamentado en distintos estatutos jurídicos.

En la medida en que desde el punto de vista de la rentabilidad nuestro Derecho urbanístico ha considerado un único destino prioritario del suelo, es entendible que el suelo no urbanizable (SNU) haya sido relegado a un segundo plano, remitiendo en buena medida el protagonismo de su ordenación a la respectiva legislación sectorial. Desde este punto de vista, se puede afirmar que los suelos rústicos son objeto de una regulación urbanística que paradójicamente "no les ordena urbanísticamente", pues la ordenación dispensada sirve precisamente para eliminar cualquier aprovechamiento urbanístico rentable en esas clases de suelo ${ }^{4}$. Ahora bien, tampoco se puede desconocer que en muchos casos esa básica ordenación "urbanística" ha sido y es la única ordenación física del territorio vigente ${ }^{5}$.

No se puede decir por tanto que sea ajeno al Derecho urbanístico la función territorial de esos terrenos ${ }^{6}$. Por un lado, porque el SNU común u ordinario ha sido utilizado como una "bolsa" potencial de suelo urbanizable, fundada en la importantísima discrecionalidad conferida al planificador a la hora de reclasificar esos terrenos ${ }^{7}$. Sin embargo, esta perspectiva no es la que nos interesa en el presente trabajo. La perspectiva que aquí nos interesa tiene que ver tanto con el SNUEP ${ }^{8}$, como con el

Derecho Urbanístico, Madrid, El Consultor, p. 113, afirma que la no indemnizabilidad derivada de la ordenación urbanística se justifica en que "la Ley parte de una situación basada en la realidad estricta, en la mera naturaleza, y que considera esa realidad natural como el único contenido inicial de la propiedad”. Por ello mismo, añade que en estos casos la Ley urbanística "no quita nada y, como no quita, tampoco reconoce indemnización alguna".

$4 \quad$ En la misma dirección, Lobato Gómez (1989: pp. 597 y 598).

5 Como señala Fernández Rodríguez (1991: pp. 134 y 135), "la LS es algo más -o, al menos, quiere serlo- que una Ley de ordenación urbana, supuesto que persigue la ordenación del territorio entero”, dispensando en SNU “un primer nivel de protección de los recursos naturales”. En la misma dirección, Parejo Alfonso, L. (1986): Derecho urbanístico. Instituciones básicas", Mendoza, p. 42, cuando afirma que "el urbanismo para la Ley del Suelo no es la ordenación de la ciudad y de su desarrollo, sino más bien equivale a lo que doctrinalmente se ha venido en llamar ordenación del territorio".

6 Cáigase en la cuenta de que estamos hablando no sólo de espacios protegidos, sino también de vastísimas superficies de "espacios intermedios”, esto es, los ubicados más allá de las zonas urbanizadas y de los espacios "oficialmente" protegidos, que ocupan el mayor porcentaje de superficie de suelo en España y que albergan la mayoría de los procesos ecológicos y productivos, aparte de ser escenario de importantes valores paisajísticos o culturales.

7 Véase, Agudo González, J. (2010a): “Mecanismos jurídicos para la limitación de la oferta de sueIo", en Revista de Derecho Urbanístico y Medio Ambiente núm. 258 y Agudo González, J. (2010b): “La 'intercambiabilidad' del suelo urbanizable y no urbanizable”, en Revista Aragonesa de Administración Pública, núm. 36.

8 Que de forma reglada el planificador debe clasificar como tal, en la medida en que el legislador, el planificador o una decisión administrativa sectorial o territorial prevalente predetermina o impone dicha clasificación urbanística. 
SNU protegido discrecionalmente por el planificador urbanístico ${ }^{9}$, es decir, todos aquellos terrenos que gozan de valores merecedores de protección. Pues bien, a estas clases de suelo el urbanismo les ha conferido un régimen jurídico compatible con sus funciones ambientales, agrarias o paisajísticas, o lo que es lo mismo, coherente con sus características físicas actuales. Sin embargo, no es correcto afirmar que tanto la clasificación, como el régimen jurídico de estos terrenos atienda exclusivamente a esas características físicas. La clasificación del SNU basada exclusivamente en aquel criterio desconoce una premisa que nuestro sistema urbanístico no ha sabido contemplar y salvaguardar: precisamente por sus características físicas actuales, el destino de los terrenos que gozan de valores merecedores de protección es la prestación de servicios ambientales a la sociedad ${ }^{10}$, lo que implica necesariamente una adscrip-

9 Las facultades discrecionales del planificador urbanístico para establecer categorías específicas de SNU protegido han sido admitidas por la jurisprudencia bajo la vigencia de las distintas Leyes estatales de suelo. En este sentido, por ejemplo, la STS de 29 de mayo de 2009 (Rec.- 283/2006; Pte.- YAGÜE GIL) en relación con la Ley 6/1998.

10 La noción de servicios ambientales supone la consideración del suelo no transformado como recurso natural que forma parte de los ecosistemas y ofrece servicios a la sociedad tanto de abastecimiento (alimentos, materias primas, recursos genéticos, etc.), como de regulación (de la composición de gases atmosféricos, del ciclo hidrológico, de la erosión, etc.) del mismo modo que servicios paisajísticos y culturales (Gómez-Limón García, J. (coord.) (2008): Plan de Acción para los espacios naturales protegidos del Estado español. Planificar para gestionar los espacios naturales protegidos, EUROPARC-España, 2008, pp. 16 y ss.). En esta dirección, como señala la Comunicación de la Europea "Detener la pérdida de Biodiversidad para 2010 y más adelante. Respaldar los servicios de los ecosistemas para el bienestar humano" [COM (2006) 216 final], "los Estados miembros tienen a este respecto una responsabilidad especial para reconciliar las necesidades de explotación y ordenación, mediante una planificación más adecuada, con la conservación de la biodiversidad y el mantenimiento de servicios de los ecosistemas".

El inconveniente fundamental de la traslación a Derecho de estos servicios es la asignación de un valor económico, en nuestro caso, de un valor urbanístico que rentabilice la apropiación de esos terrenos, máxime si como señala la Comunicación de la Comisión [COM (2006) 216 final], "estos servicios sustentan el crecimiento, el empleo y el bienestar en la Unión Europea”. A la misma conclusión se llega por GómezLimón García (2008: pp. 16 a 18), en el que se afirma que "los ecosistemas naturales y seminaturales producen beneficios indispensables para la economía, la salud pública y el bienestar general de los seres humanos. Se entiende por tanto que un ecosistema con un buen nivel de integridad o salud ecológica constituye un capital natural, ya que algunas de sus funciones ecológicas generan servicios a la sociedad, tengan o no valor económico en el mercado".

Nuestro ordenamiento ya ha reconocido expresamente la noción de servicios ambientales, y lo ha hecho ensanchando de forma muy importante su adscripción territorial: $1^{\circ}$ ) Por un lado, se mantiene una relación lógica entre espacios naturales protegidos y prestación de servicios ambientales. Así, el art. 2.a) de la Ley 42/2007, de 13 de diciembre, del Patrimonio Natural y de la Biodiversidad, establece entre los principios que inspiran la Ley "el mantenimiento de los procesos ecológicos esenciales y de los sistemas vitales básicos, respaldando los servicios de los ecosistemas para el bienestar humano". Asimismo, el art. 73 de la Ley, relativo a los incentivos a las externalidades positivas en el ámbito de los espacios protegidos, establece que las CCAA deberán incentivar "las externalidades positivas de terrenos que se hallen ubicados en espacios declarados protegidos o en los cuales existan acuerdos de custodia del territorio debidamente formalizados" (regulados en el art. 72), para lo cual tendrán en cuenta "los servicios prestados por los ecosistemas"; $2 .^{\circ}$ ) Por otra parte, el vastísimo concepto de "monte" que acoge la Ley 43/2003, de 21 de noviembre, de Montes, está vinculado también a la prestación de ese tipo de servicios. Así, el art. 4 de la Ley 43/2003 establece que "los montes, independientemente de su titularidad, desempeñan una función social relevante, tanto como fuente de recursos naturales como por ser proveedores de múltiples servicios ambientales, entre ellos, de protección del suelo y del ciclo hidrológico; de fijación del carbono atmosférico; de depósito de la diversidad biológica y como elementos fundamentales del paisaje"; $3 .^{\circ}$ ) El Convenio Europeo del Paisaje confirma esa visión amplificadora con base en una definición de "paisaje" que poco tiene 
ción permanente a dicho destino, salvo pérdida acreditada como consecuencia de procesos naturales de los valores que habilitan su adscripción a la prestación de esos servicios.

Nuestro Derecho urbanístico no ha considerado convenientemente este dato fundamental. No en vano, los servicios ambientales prestados por los terrenos rústicos que gozan de valores merecedores de protección sólo han sido considerados a los efectos de justificar limitaciones a las facultades urbanísticas de los propietarios con base en la función social que define el derecho de propiedad. En consecuencia, los propietarios de esos terrenos han soportado y soportan el coste de la prestación de servicios ambientales que favorecen y benefician a toda la sociedad sin que ello se traduzca en un contenido urbanístico que valorice la propiedad del suelo y sin que en principio ello conlleve contraprestación alguna.

Así pues, la visión proteccionista del Derecho en relación con estos terrenos ha justificado que su régimen jurídico se caracterice por la "congelación" de todas las facultades urbanísticas (y en muchos casos de otro tipo) y el reconocimiento de una limitación general del ius aedificandi, unida a un aplazamiento indefinido de dicha prohibición. En estos términos, es difícil no afirmar que el régimen jurídico que impone la concepción estatutaria de la propiedad, justificada en su función social, no supere en muchos casos la frontera de la rentabilidad inherente a la titularidad del derecho. En otras palabras, el impacto sobre las facultades del propietario puede ser tan gravoso,

\footnotetext{
que ver con la noción tradicional que hemos empleado en nuestro ordenamiento vinculada a la protección de espacios y lugares emblemáticos, así como de bellezas naturales. El paisaje es concebido por el Convenio como el territorio percibido por la sociedad, expresión de la evolución natural y de la influencia humana, síntesis de las nociones tradicionales de paisaje natural y de paisaje cultural, ampliado sobre la matriz envolvente que es el territorio [en este sentido, Zoido Naranjo, F. (2001): "La Convención Europea del Paisaje y su aplicación en España”, en Revista Ciudad y Territorio-Estudio Territoriales, núm. XXXIII (128), pp. 276 y 277; en la misma línea, Lasagabaster Herrarte, I. y Lazcano Brotóns, I. (2004): "Protección del paisaje, ordenación del territorio y espacios naturales protegidos", en Revista Vasca de Administración Pública, núm. 70, p. 131]. La sustanciosa definición de paisaje que asume la Convención supone dar un salto cualitativo espectacular para aterrizar en un concepto netamente expresivo de la "territorialidad" del paisaje. Esta territorialización del paisaje es plena, de modo que puede afirmarse sin ambages que para la Convención “todo territorio es paisaje” [Mata Olmo, R. (2006): “Un concepto de paisaje para la gestión sostenible del territorio", en Mata Olmo, R. y Tarroja Coscuela, A. (coords.), El paisaje y la gestión del territorio. Criterios paisajísticos en la ordenación del territorio y el urbanismo, Barcelona, Diputación de Barcelona y CUIMPB, p. 23, y Tarroja Coscuela, A. (2006): "Transformaciones territoriales y valoración social del paisaje", en Mata Olmo, R. y Tarroja Coscuela, A. (coords.), El paisaje y la gestión del territorio. Criterios paisajísticos en la ordenación del territorio y el urbanismo, Barcelona, Diputación de Barcelona y CUIMPB, p. 45; Zoido Naranjo (2001: p. 277) o en Zoido Naranjo, F. (2000): “Estudios sobre el paisaje”, en Martínez de Pisón, I. (dir.), Madrid, p. 297, o Lasagabaster Herrarte y Lazcano Brotóns (2004: p. 129)]. Este amplio concepto es expresivo de cómo las implicaciones del paisaje en las distintas políticas públicas no se pueden limitar a la protección de lo notable, sino también a la gestión de muchos otros paisajes no significativos. En coherencia con ello se entiende que la Convención amplíe su ámbito aplicativo a todo el territorio de los Estados parte, comprendiendo "los paisajes que puedan considerarse excepcionales como los paisajes cotidianos o degradados" (art. 2). Pues bien, desde la perspectiva de la noción de servicios ambientales, cabría afirmar también que todo territorio presta servicios paisajísticos que reclaman su consideración en las distintas políticas públicas con trascendencia territorial. Sobre la materia véase Agudo González, J. (2007): “Paisaje, gestión del territorio y patrimonio histórico", en Revista Patrimonio Cultural y Derecho núm. 11.
} 
que puede ser calificada como una auténtica expropiación o quizás mejor de una "expropiación expectante" "11.

No obstante esta conclusión, en la lógica del sistema estatutario de la propiedad no cabría imputar a los suelos rústicos plusvalías semejantes a las conferidas en suelo urbanizable, pues los servicios ambientales que prestan estos suelos son intrínsecos a la propia naturaleza de esos terrenos ${ }^{12}$. Esta conclusión supone, lisa y llanamente, que el beneficio público derivado de la clasificación del suelo como SNU no sólo no es compensado con facultades equiparables en contenido económico a las atribuidas a los propietarios de suelo urbanizable, sino que las cargas que ello pueda suponer son imputadas íntegramente a los propietarios de esos suelos, sin contenido urbanísticopatrimonial alguno ${ }^{13} \mathrm{y}$, en principio, a coste cero. En definitiva, no sólo se ha privado a los propietarios de un aprovechamiento rentable que defina la apropiación de esos terrenos, sino que además el régimen jurídico de esos terrenos supone la práctica identificación de la vertiente subjetiva del derecho propiedad con las cargas y deberes imputables a los propietarios.

El no reconocimiento de ninguna trascendencia sustancial jurídico-urbanístico a la prestación de servicios ambientales vinculada a la propiedad del suelo, está en la base de los problemas de insostenibilidad territorial de nuestro urbanismo, configurado como un modelo de oferta de suelo: el "urbanismo rentable", que sólo genera plusvalías en suelo urbanizable, incentiva a los propietarios de SNU a obtener una rentabilidad similar que no pueden alcanzar si mantienen el mismo estatuto jurídico. Consecuentemente, el único modo de lograrlo es promover la reclasificación de sus terrenos.

Para evitar esa perniciosa dinámica, el ordenamiento jurídico ha previsto mecanismos jurídicos diversos cuya finalidad es rebajar las obligaciones que supone la prestación de servicios ambientales mediante la colectivización de las cargas derivadas de la prestación de tales servicios. Desde esta perspectiva, el Derecho urbanístico y medioambiental ha previsto algunos instrumentos de fomento para contribuir económicamente a las cargas que caracterizan al régimen jurídico del SNU protegido. No obstante, aparte de su aplicación limitada, todos esos instrumentos suponen reconocer de forma tácita el planteamiento precedente: son compensaciones que sirven

11 Sin embargo, ni siquiera en supuestos como estos el Tribunal Constitucional ha dudado en mantener la constitucionalidad del régimen limitativo de la propiedad, ya en nuestro caso en relación con el SNU (SSTC 61/1997 y 164/2001), pero también con la protección del patrimonio histórico-artístico (STC 17/1991), o con los terrenos sometidos a servidumbres en relación con el dominio público hidráulico o marítimo-terrestre (SSTC 227/1988 y 149/1991), o bien con los inmuebles sometidos a prórroga forzosa en los arrendamientos urbanos (STC 89/1994).

12 El concepto de "plusvalía", según el Diccionario de la Real Academia de la Lengua, hace referencia al "acrecentamiento del valor de una cosa por causas extrínsecas a ella". Por este motivo, el beneficio privado derivado de la clasificación del suelo debe ser compensado y repercutido en la comunidad (art. 47 de la Constitución) en coherencia con el origen artificial y otorgado de esas plusvalías.

13 Lobato Gómez (1989: p. 521), habla desde una perspectiva parecida, de que éste es uno de los problemas sin resolver de nuestro urbanismo. 
para contribuir al costeamiento de la ejecución de las obligaciones inherentes a la función social de la propiedad, pero que no valorizan "urbanísticamente" la propiedad del suelo en sí misma.

Estos mecanismos han sido complementados y superados en algunas CCAA en las que diversas técnicas urbanísticas tradicionales son empleadas para integrar al SNU que presta servicios ambientales en el marco de una ordenación y gestión urbanística integral ${ }^{14}$. Precisamente a esos mecanismos son a los que vamos a dedicar nuestras reflexiones en este trabajo. Aunque como vamos a mostrar los mecanismos utilizados sean diversos, los más avanzados condicionan la reclasificación de suelo y, por consiguiente, el otorgamiento de aprovechamientos a los nuevos propietarios de suelo urbanizable, al resarcimiento de los propietarios de SNU que prestan servicios ambientales.

En estos supuestos, los datos fundamentales son varios. En primer lugar, si esa compensación a la que hacemos referencia constituye una "liberación" definitiva de la "expropiación expectante" a la que somete la legislación sectorial y urbanística a los terrenos que prestan servicios ambientales o si, por el contrario, supone una atribución de un contenido urbanístico a las facultades del propietario, quien continua en su condición de titular del suelo. Aquí, ya lo anticipamos, la regulación más moderna de las CCAA antes aludidas se mantiene en la primera posibilidad, pues en todo caso se prevé la adquisición de tales terrenos por la Administración actuante. En fin, la idea es corregir el perjuicio patrimonial que supone mantenerse indefinidamente como propietario de terrenos proveedores de servicios ambientales carentes de rentabilidad económica, pero con una solución paradójica, pues en última instancia, aquella falta rentabilidad no se suple, sino que directamente se excluye con la eliminación del derecho de propiedad. En otras palabras, en estricto cumplimiento del sentido genuino de la concepción estatutaria de la propiedad, en ningún caso se otorga un definitivo contenido sustancial de naturaleza urbanística a la relación de apropiación que define el derecho de propiedad, lo que sitúa a estos instrumentos más cerca de las técnicas tradicionales de fomento de lo que podría parecer a primera vista.

Otra cuestión a considerar en relación con estos nuevos mecanismos es quién soporta esa compensación. Aquí las soluciones son variables según las CCAA, pero pueden cifrarse en dos: $1 .^{a}$ ) La imputación indirecta de las cargas a las plusvalías generadas en nuevos desarrollos urbanísticos. Se trata por tanto de una colectivización parcial de aquellas cargas, pues en este caso es la Administración actuante quien, con base en el aprovechamiento no susceptible de apropiación privada y de cesión obligatoria, puede promover la redistribución de las plusvalías favoreciendo a quienes 
prestan servicios ambientales (véase el epígrafe 2.1.); 2. ${ }^{\text {) }}$ La imputación directa de las cargas a los propietarios: aquí son directamente los propietarios beneficiados por la reclasificación del suelo y por el otorgamiento sobrevenido de aprovechamientos quienes tienen el deber de resarcir o compensar a quienes prestan servicios ambientales a favor de toda la sociedad (epígrafe 2.2.). Este segundo supuesto es el más relevante y destacado, pues como mostraremos más adelante, supone el otorgamiento de aprovechamientos urbanísticos a terrenos clasificados como SNU, eso sí, como una manifestación más de la recuperación por la comunidad de las plusvalías, pues se articula como una expresión adicional del deber legal previsto en el art. 16.1.a) del TRLS de 2008.

Como se habrá podido observar, en última instancia la fuente de financiación del resarcimiento de los prestadores de servicios ambientales son los aprovechamientos del nuevo suelo urbanizable. Las razones para ello son sencillas: $1 .^{a}$ ) El aprovechamiento urbanístico, según la concepción estatutaria de la propiedad, se incorpora al patrimonio de los propietarios de suelo con base en una decisión pública que beneficia a tales propietarios y que legitima el consumo de recursos naturales; $2 .^{a}$ ) Los propietarios de suelos prestadores de servicios ambientales, aparte de que en principio nunca se verán favorecidos por decisiones similares, deben ver resarcidas parcialmente las cargas que la legislación urbanística y sectorial les impone con base en aquellas plusvalías, pues los mandatos del legislador y del planificador urbanístico y sectorial les sitúa como defensores y protectores a favor de toda la comunidad y a largo plazo del mismo recurso escaso que consumen las actuaciones urbanísticas en suelo urbanizable; $3 .^{\text {a) }}$ La conexión entre las dos premisas anteriores evita la colectivización total y general de las cargas sobre toda la comunidad (ya mediante la expropiación, ya mediante el pago de ayudas), centrando el resarcimiento en los únicos propietarios que obtienen una manifiesta rentabilidad con base en las decisiones públicas, sin perjuicio lógicamente de la aplicación complementaria de otros mecanismos de colectivización (medidas tradicionales de fomento); y $4 .^{\mathrm{a}}$ ) En la medida en que la clasificación de suelo urbanizable estaría condicionada por la ordenación urbanística del SNU que presta servicios ambientales, también la materialización del aprovechamiento atribuible a sus propietarios deberá realizarse en los únicos terrenos que por su régimen jurídico admiten la ejecución de usos urbanísticos lucrativos, esto es, el suelo urbanizable.

Aunque insistimos que los mecanismos son variables y la profundidad de sus medidas también, lo que todas ellas ponen de relieve es un paso al frente hacia una visión renovada del derecho de propiedad inmobiliaria y de la función pública urbanística. Este nuevo planteamiento, en la medida en que pone de relieve la necesidad de una ordenación urbanística integral de todo el suelo, incluido el SNU, nos encamina hacia la sustantivización actual del derecho de propiedad inmobiliaria. En otras palabras, los avances en esta línea podrán ser más o menos trascendentes, pero nos encaminan hacia un urbanismo en el que partiendo del reconocimiento de situacio142 nes jurídicas variables, todas ellas incorporen un contenido subjetivo (aprovecha- 
mientos inherentes a todo propietario) que otorgue una rentabilidad real y no potencial a los propietarios.

\section{INSTRUMENTOS JURÍDICOS PARA LA GESTIÓN INTEGRAL DEL SUELO}

\subsection{La redistribución de las plusvalías generadas en suelo urbanizable mediante la aplicación de los instrumentos de intervención administrativa en el mercado del suelo: la adquisición de terrenos prestadores de servicios ambientales y la colectivización de las cargas}

La transferencia de las plusvalías generadas en suelo urbanizable a los suelos que prestan servicios ambientales puede articularse a través de los mecanismos de intervención de la Administración en el mercado del suelo que prevé la legislación urbanística, en lo que podría calificarse como una primera aproximación, de menor calado, a la gestión integral del suelo. En este caso, la gestión de los aprovechamientos no susceptibles de apropiación cedidos a la Administración urbanística ope legis con el fin de resarcir a los propietarios de SNU constituiría un mecanismo idóneo, pues aunque supondría una colectivización relativa de las cargas imputables a los propietarios de suelo que prestan servicios ambientales (en contraprestación con la generalidad y globalidad del servicio), en realidad el coste sería nulo (ya que la carga se financia con base en aprovechamientos cedidos gratuitamente y libres de cargas).

En esta dirección, los Patrimonios Públicos de Suelo pueden comenzar a tener un protagonismo importante. Hasta la entrada en vigor de la Ley 8/2007, de 28 de mayo, de Suelo, los arts. 276 y 280.1 del TRLS de 1992 fueron los preceptos que establecieron los destinos básicos de los bienes integrantes de los Patrimonios Públicos de Suelo. Mientras que el art. 276.1 disponía que la finalidad de estos Patrimonios era "regular el mercado de terrenos, obtener reservas de suelo para actuaciones de iniciativa pública y facilitar la ejecución del planeamiento”, el art. 280.1 añadía que los bienes de los Patrimonios Públicos de Suelo debían "ser destinados a la construcción de viviendas sujetas a algún régimen de protección pública o a otros usos de interés social”. Ambos preceptos tenían el carácter de legislación básica en virtud del art. 149.1.13 CE (normas básicas relativas a la planificación general de la actividad económica). No obstante, la competencia estatal fundamentada en el art. 149.1.13 debía ser entendida de forma restrictiva, como así puso de manifiesto la STC 61/19975. Desde

15 Afirma a este respecto la STC 61/1997 que "tan sólo aquellas normas básicas que respondan efectiva y estrictamente a la planificación de la actividad económica podrían encontrar cobijo en el referido título, que impide la producción de normas que, aunque relacionadas con esa planificación general, no guarden esa inmediata y directa relación con la dirección de la economía. Desde esta perspectiva, podría encontrar cobertura en el citado título estatal la mera determinación de la existencia de una figura como la que contempla el art. 276 TRLS", añadiendo al analizar el contenido del art. 280 que "resulta elocuente el carácter no básico del apartado 2 del mismo artículo, tampoco impugnado, que concreta y desarrolla el principio general del destino de tales bienes". 
esta perspectiva, se puede decir que al Estado le correspondía y le corresponde fijar fines genéricos sobre el destino de los bienes del Patrimonio Público de Suelo, que en todo caso constituyan un marco referencial que para las CCAA, pero que sin agotar su regulación, permitan su concreción y desarrollo por las CCAA.Siguiendo las directrices de la jurisprudencia constitucional, el legislador autonómico asumió prontamente una labor de pormenorización del destino de los bienes integrantes de los Patrimonios Públicos de Suelo ${ }^{16}$. Esa ampliación ha supuesto una flexibilización de la consideración de los Patrimonios Públicos de Suelo como "un fondo rotatorio de retroalimentación”, regido por el principio de subrogación real, pues algunos de esos destinos (uso dotacional público, cesiones gratuitas) irremediablemente suponen la imposibilidad del cumplimiento del principio "Patrimonio llama a Patrimonio". Es por este motivo que el principio de integridad de los Patrimonios Públicos de Suelo que ha sido una constante en nuestro Derecho (desde el art. 276.2 último inciso del TRLS de 1992 a las Leyes autonómicas en vigor), y que todavía está vigente (así lo confirma el art. 38.2 del TRLS de 2008), requiere ser interpretado con la flexibilidad suficiente ${ }^{17}$, como para entender que el fin de los Patrimonios Públicos de Suelo no es tanto su integridad absoluta, como su revalorización.

La Ley 8/2007 y el vigente TRLS de 2008 confirman esa evolución. Sin perjuicio de mantener el principio de integridad de los Patrimonios Públicos de Suelo y un destino prioritario coincidente con el tradicional de nuestro Derecho urbanístico (construcción de vivienda sujeta a algún régimen de protección pública) ${ }^{18}$, el vigente art. 39.1 dispone que los bienes integrantes de los Patrimonios Públicos de Suelo se podrán destinar "a otros usos de interés social de acuerdo con lo que dispongan los instrumentos de ordenación urbanística, sólo cuando así lo prevea la legislación en la materia especificando los fines admisibles, que serán urbanísticos o de pro-

16 Algunos ejemplos en los siguientes preceptos: art. 176 de la Ley 9/2001 de la Comunidad de Madrid, art. 125 de la Ley 5/1999 de Castilla y León según ha quedado redactado por Ley 4/2008, art. 79 del Decreto Legislativo 1/2004 de Castilla-La Mancha, art. 224 del Decreto 305/2006 de Cataluña, art. 181 de la Ley 5/2006 de La Rioja, art. 111 de la Ley 3/2009 de Aragón, art. 75 de la Ley 7/2002 de Andalucía, art. 198 de la Ley 1/2001 de Murcia, art. 92 de la Ley 15/2001 de Extremadura, art. 227 de la Ley Foral 35/2002 de Navarra, o el art. 76 del Decreto Legislativo $1 / 2000$ de Canarias.

17 En esta línea, Menéndez Rexach, A. (2007): “Artículos 33 y 34”, en Sánchez Goyanes, E. (dir.), Ley de Suelo. Comentario sistemático de la Ley 8/2007, de 28 de mayo, de Suelo, Madrid, La Ley, p. 852; Quintana López, T. (2004): “La regulación de los Patrimonios Públicos del Suelo como fuente de controversia”, en Revista Española de Derecho Administrativo núm. 121, p. 83; Blanquer Criado, D. (2007): Los Patrimonios Públicos del Suelo, Tirant lo Blanch, Valencia, p. 379; Delgado Piqueras, F. (2008): “Novedades del régimen básico de los patrimonios públicos de suelo”, en Revista de Derecho Urbanístico y del Medio Ambiente, núm. 240, pp. 61 y ss.; Martín Hernández, P. (2006): "El patrimonio municipal del suelo: su evolución normativa”, en Revista de Derecho Urbanístico y del Medio Ambiente, núm. 225, p. 288; Agudo González, J. (2004): “Desafectación y compensación de terrenos dotacionales, como premisa para su permuta por obra futura”, en Revista de Derecho Urbanístico y del Medio Ambiente, núm. 213, pp. 62 y ss.

18 Parejo Alfonso, L. y Roger Fernández, G. (2007): Comentarios a la Ley de Suelo (Ley 8/2007, de 28 de mayo), Madrid, lustel, p. 381, y Menéndez Rexach (2007: p. 847), afirman que los fines genéricos de los bienes de los Patrimonios Públicos de Suelo establecidos en la norma estatal no se sitúan en pie de igual144 dad, ya que la construcción de vivienda sujeta a algún régimen de protección pública sigue siendo el destino primario. 
tección o mejora de espacios naturales o de los bienes inmuebles de patrimonio cultural" 19 . Con ello se sale al paso de una extensa línea jurisprudencial que había venido aplicando de forma restrictiva el antiguo art. 280.1 del TRLS de 1992, impidiendo el destino de bienes del Patrimonio Público de Suelo a otros "usos de interés social" ${ }^{20}$. Por otra parte, la remisión del art. 39.1 del TRLS de 2008 a la legislación autonómica vendría a confirmar la flexibilidad del destino de los bienes del Patrimonio Público de Suelo que las Leyes vigentes habían venido asumiendo años atrás ${ }^{21}$.

Esta amplitud renovada de los destinos de los bienes integrantes de los Patrimonios Públicos de Suelo afecta expresamente al objeto de nuestro estudio. Entre los destinos secundarios a los que hace alusión el art. 39.1 in fine del TRLS de 2008 se encuentra la "protección o mejora de espacios naturales"22. No obstante, no cabe decir que esta previsión sea una novedad, pues con anterioridad varias CCAA ${ }^{23}$ ya habían previsto esa función ambiental y paisajística de los Patrimonios Públicos de Suelo ${ }^{24}$. De la nueva regulación legal sí que cabe destacar la amplitud con que se prevé aquella función ambiental de los Patrimonios Públicos de Suelo. En concreto, se hace referencia a la protección o mejora de los "espacios naturales", y no sólo a los espacios naturales protegidos, lo que conecta este específico destino de los bienes de los Pa-

19 En otras palabras, el nuevo precepto concreta y amplía de forma considerable el inciso final del art. antiguo 280.1 TRLS de 1992, en virtud del cual los bienes de los Patrimonios Públicos de Suelo debían "ser destinados a la construcción de viviendas sujetas a algún régimen de protección pública o a otros usos de interés social".

20 Un repaso de esa jurisprudencia en Menéndez Rexach (2007: pp. 849 y ss.), así como en Blanquer Criado (2007: pp. 331 y ss.).

21 Confirmaría esta conclusión, el hecho de que de las Leyes aprobadas por las CCAA para adaptar su legislación a la Ley 8/2007, sólo Castilla y León y Aragón hayan modificado el precepto legal que regulaba el destino de los bienes de los Patrimonios Públicos de Suelo.

22 En el mismo sentido, el art. 125.1.e) de la Ley 5/1999 de Castilla y León según ha quedado redactado por Ley $4 / 2008$.

23 Algunas CCAA se limitaban a establecer una previsión genérica relativa a la "conservación y mejora del medio ambiente” [art. 181.b) de la Ley 5/2006 de La Rioja, art. 176.b) de la Ley 9/2001 de Madrid, art. 79.1.b) del Decreto Legislativo 1/2004 de Castilla-L Mancha, art. 177.1.d) de la Ley 9/2002 de Galicia]; otras aludían a la protección y tutela del SNU y a la "conservación y mejora del medio rural y natural” [arts. 153.4.d) del Decreto Legislativo 1/2005 y 224.2.e) del Decreto 305/2006 de Cataluña]; finalmente otras se referían a "la financiación de actuaciones de interés social para la protección, mejora o recuperación del entorno urbano, territorio y paisaje” (art. 86 de la Ley 4/2004 de ordenación del territorio y paisaje de la Comunidad Valenciana).

La normativa que con anterioridad a la Ley estatal 8/2007 mejor reflejaba esta función es la canaria. En primer lugar, el art. 76.b) del Decreto Legislativo 1/2000 de Canarias establece como destino genérico de los bienes que integran los Patrimonios Públicos de Suelo la "conservación y mejora del medio ambiente”. Pues bien, el art. 232.1. .a) y b) del Decreto 183/2004, de 21 de diciembre, por el que se aprueba el Reglamento de gestión y ejecución del sistema de planeamiento de Canarias, añade que la Administración de la Comunidad Autónoma, los Cabildos Insulares y los Municipios deberán constituir sus respectivos Patrimonios Públicos de Suelo, con las finalidades siguientes: “a) Creación de reservas de suelo para actuaciones públicas de carácter urbanístico, residencial o ambiental y facilitar el planeamiento de ordenación así como su ejecución; b) Creación de espacios de interés ambiental con la finalidad de restauración de ecosistemas frágiles, escasos o amenazados, la protección de hábitat o especies amenazadas u otros de similar carácter a fin de garantizar la conservación y recuperación de determinados recursos naturales".

24 Utilizando los términos de Blanquer Criado (2007: pp. 380 y ss.). 
trimonios Públicos de Suelo con el suelo en situación básica rural preservada del art. 12.2.a) del TRLS de 2008, esto es, justamente los que aquí hemos calificado como suelos prestadores de servicios ambientales.

Partiendo de esta consideración, cabría sostener una política de adquisición de terrenos prestadores de servicios ambientales, financiando tal adquisición con los recursos provenientes de los Patrimonios Públicos de Suelo ${ }^{25}$ (insistimos en concreto con base en el aprovechamiento no susceptible de apropiación cedido por los propietarios de suelo urbanizable). Esa política además se podría llevar a cabo no sólo a nivel local, sino también a nivel autonómico, pues la constitución de Patrimonios Públicos de Suelo autonómicos es una imposición legal que si bien puede deducirse implícita del art. 38.1 del TRLS de 2008, en todo caso es un deber expreso en las CCAA de Andalucía, Cantabria, Castilla-La Mancha, Extremadura, Murcia, Madrid, Comunidad Valenciana, Canarias o Navarra.

En fin, la creación y ampliación de los Patrimonios Públicos de Suelo con suelo destinado a fines ambientales y paisajísticos se puede articular por tanto con base en los mismos instrumentos que hasta ahora habían sido utilizados para generar nueva oferta de suelo, esto es, para fines radicalmente distintos a los que ahora se proponen, pero coherentes con los principios que definen la legislación de suelo estatal vigente.

El primer mecanismo para articular aquella adquisición de terrenos, en orden al establecimiento de una estrategia en la línea señalada, podrían ser las reservas de suelo. Como es bien sabido, la delimitación de reservas de terrenos tiene una doble consecuencia jurídica (así se preveía ya en el art. 278.4 del TRLS de 1992 y ha sido acogido por todas las Leyes autonómicas): a) La declaración de la utilidad pública a efectos expropiatorios por un tiempo máximo, debiendo iniciarse el expediente expropiatorio en tal plazo; b) La sujeción de todas las transmisiones que se efectúen en las reservas de terrenos a los derechos de tanteo y retracto a favor de la Administración que proceda.

La aplicación de estos instrumentos para fines como los que venimos comentando, obviamente exige entender que tales reservas puedan afectar a suelo clasificado como SNU ${ }^{26}$. Sin embargo, las reservas en SNU han sido comunes en nuestro Derecho,

25 En este sentido, el art. 86 de la Ley 4/2004, de 30 de junio, de ordenación del territorio y paisaje de la Comunidad Valenciana.

26 Por otro lado, respecto de la motivación de la finalidad de la reserva, debemos señalar que a partir de la STS de 21 de mayo de 2003 (Az. 5363) el Tribunal Supremo modificó su doctrina sobre esta materia, considerando determinante la especificación de los fines de la reserva. En otro caso, o mejor, como sucedía hasta la sentencia recién transcrita, se entregaba a la Administración, con una discrecionalidad amplísima, la decisión sobre cuál debiera de ser finalmente el destino definitivo de los terrenos, lo que en la práctica permitía justificar casi cualquier reserva de suelo, incluso con superficies absolutamente 146 desproporcionadas, encubriendo una "municipalización" del suelo y de los aprovechamientos urbanísticos que pudieran generarse en el término municipal. En definitiva, un instrumento excepcional que permi- 
si bien con objetivos muy distintos ${ }^{27}$. Tampoco las reservas en SNUEP o en general en suelos que prestan servicios ambientales son ajenas a nuestro Derecho. Ahora bien, precisamente por los valores que caracterizan a esos terrenos se entiende que esas reservas guarden necesariamente ciertas particularidades. Es decir, la reserva de terrenos en esta clase de suelo debe estar vinculada forzosamente a fines ambientales, pues otra cosa supondría desnaturalizar de raíz el régimen jurídico del SNUEP y del SNU protegido por el planificador urbanístico a través de esta vía indirecta, legitimando así reclasificaciones de suelo y/o usos del suelo que nunca habrían sido aprobados o autorizados en aplicación del régimen ordinario propio de estas clases de suelo.

El Decreto 183/2004 de la Comunidad de Canarias confirma esta conclusión en su art. 235. El apartado $1 .^{\circ}$ de este precepto establece que "el planeamiento podrá establecer, en cualquier clase de suelo, reservas de terrenos de posible adquisición para la constitución o ampliación por la Administración correspondiente de su Patrimonio Público de Suelo". Pues bien, en la medida en que las reservas pueden ser establecidas también en SNUEP, el apartado $2 .^{\circ}$ del art. 235 concluye lo siguiente: "El planeamiento de ordenación de los recursos naturales y territorial establecerá específicamente en espacios naturales protegidos la reserva de los ámbitos de mayor valor en biodiversidad o estratégicos para su recuperación, con el fin de incorporar en el patrimonio público una muestra de los hábitat mejor conservados, así como de las especies endémicas de la fauna y flora de Canarias y de cada isla. En el caso de los Parques Rurales, la constitución de reservas atenderá, junto a los fines de conservación, al objeto de contribuir al desarrollo socioeconómico de las poblaciones asentadas en ellos"28.

te gestionar suelo fuera de las determinaciones de planeamiento, se había convertido en un instrumento relativamente habitual para adquirir suelo barato y dar solución a "problemas urbanísticos generales que pueden ser resueltos al margen de la figura del Patrimonio Municipal del Suelo", por utilizar los términos de la STS de 21 de mayo de 2003 (Az. 5363).

27 La vigente legislación urbanística reconoce la posibilidad de prever reservas en SNU, al mismo tiempo que ha ampliado, como ya hemos mencionado, los fines de los bienes integrantes de los Patrimonios Públicos del Suelo. Aunque no en todas las CCAA se ha previsto la posibilidad de realizar reservas en SNU (caso de Asturias, Cantabria, Castilla y León, Galicia y Murcia), la realidad es que por regla general o bien se prevé su delimitación “en cualquier clase de suelo" (Canarias, Madrid o Comunidad Valenciana), o bien específicamente se admiten reservas en SNU común (Cataluña, Extremadura, La Rioja, Navarra o Andalucía), o bien en alguna categoría específica del SNU ordinario (en suelo rústico de reserva en el caso de Castilla-La Mancha).

28 En otras CCAA se prevén reservas en SNU con fines ambientales de una forma bastante más genérica. En el caso de Andalucía, el art. 73.1 de la Ley 7/2002 establece que las reservas se "podrán establecer en cualquier clase de suelo", pero en su apartado 2. se concreta que "el objeto de estas reservas será, de acuerdo con la clasificación de los suelos". Por esta razón, la letra c) de este precepto fija los fines de las reservas en SNU, señalando que éstas podrán tener como objeto "actuaciones públicas de viviendas en aquellas zonas donde se prevea el crecimiento de la ciudad, siendo el destino predominante el de viviendas sujetas a algún régimen de protección pública, o para otros usos industriales, terciarios o turísticos, salvo que la finalidad de la reserva sea la de contribuir a la protección o preservación de las características del suelo no urbanizable o de cumplir determinadas funciones estratégicas de ordenación o vertebración territorial". Parece claro que en caso de que la reserva afecte a SNUEP sólo cabría establecer reservas cuyo objeto recaiga en el inciso resaltado en cursiva. En la misma dirección, el art. 119.2 de la Ley 2/2006 del País Vasco, en virtud del cual “también podrán delimitarse reservas en suelo no urbanizable de especial protección con el objeto de facilitar la obtención de la propiedad pública y, en su caso, la explotación o utilización adecuada del mismo". 
La delimitación de reservas en SNU no sólo habilitaría a la Administración a la expropiación de esos terrenos, sino también a la adquisición preferente de los mismos mediante el ejercicio de los derechos de tanteo y retracto. No obstante, estos derechos de adquisición preferente no necesariamente tienen por qué estar vinculados a la delimitación de una reserva de suelo. De hecho, prácticamente todas las CCAA han previsto la facultad de las Administraciones urbanísticas de delimitar áreas en las que las transmisiones onerosas de terrenos quedan sujetas al ejercicio por la Administración actuante de los derechos de tanteo y retracto a efectos de garantizar el cumplimiento de la programación de los instrumentos de planeamiento, o bien para incrementar los Patrimonios Públicos de Suelo, o bien para intervenir en el mercado inmobiliario. Asimismo, también ha sido tradicional en nuestro Derecho vincular estos derechos de adquisición preferente como una consecuencia de la declaración de espacios naturales protegidos ${ }^{29}$ e incluso de otros espacios protegidos por sus condiciones naturales (art. 25 de la Ley de Montes).

Los derechos de tanteo y retracto, con independencia de su ejercicio como un mecanismo de intervención en el mercado del suelo o como una consecuencia jurídica de la protección específica de un espacio natural, son también un instrumento para la obtención de suelos en la dirección analizada. En algunas CCAA los derechos de tanteo y retracto, concebidos como instrumentos de intervención en el mercado del suelo articulados a través de los Patrimonios Públicos de Suelo, son vinculados específicamente a la obtención de suelo en espacios protegidos. El problema en estos casos es que los derechos de adquisición preferente se limitan a esos espacios protegidos, en términos similares a los previstos en la legislación de espacios naturales protegidos, olvidando por tanto su aplicación a otros terrenos con valores merecedores de protección. Sólo en las CCAA donde la Ley prevé de forma genérica la delimitación de reservas en SNUº,

En otras CCAA una posibilidad similar se deduce, porque se prevé de forma genérica la reserva de terrenos en cualquier clase de suelo y sin restricción alguna (art. 261.1 de la Ley 16/2005 de la Comunidad Valenciana y art. 175.1 de la Ley 9/2001 de la Comunidad de Madrid). Eso sí, aunque en esas CCAA no se establece un destino específico para los terrenos así obtenidos, tanto en la Comunidad Valenciana, como en la Comunidad de Madrid se prevé expresamente que los bienes integrados en los Patrimonios Públicos de Suelo (sin consideración al modo de incorporación) puedan ser destinados a "la financiación de actuaciones de interés social para la protección, mejora o recuperación del entorno urbano, territorio y paisaje" (art. 86 de la Ley 4/2004 de la Comunidad Valenciana), o bien a la "conservación y mejora del medio ambiente" [art. 176.b) de la Ley 9/2001 de Madrid].

29 Así lo era con base en el art. 10.3 de la Ley 4/1989, de 27 de marzo, de protección de los Espacios Naturales y de la Flora y Fauna Silvestres, y así lo es en virtud del art. 39 de la Ley 42/2007, de 13 de diciembre, del Patrimonio Natural y de la Biodiversidad, y del art. 13 de la Ley 5/2007, de 3 de abril, relativa a la Red de Parques Nacionales.

30 En Andalucía o La Rioja la Ley alude a esta posibilidad señalando que cabe delimitar reservas "en cualquier clase de suelo", algo que también es previsto en Asturias pero sólo para las reservas regionales. En Extremadura y Canarias se prevé esta posibilidad, pero con referencia específica a zonas protegidas. En la Comunidad de Madrid, aparte de poder delimitar reservas en espacios protegidos, también cabe esa posibilidad de forma genérica para el SNU. Finalmente en Castilla-La Mancha se prevé esa facultad de

148 forma genérica para el suelo rústico. 
parecería posible implementar una política de adquisición de terrenos con objetivos más amplios que los señalados ${ }^{31}$.

\subsection{La gestión urbanística conjunta de todo el suelo, incluido el suelo no urbanizable, mediante la aplicación de técnicas equidistributivas: la cesión de terrenos prestadores de servicios ambientales a cambio de aprovechamiento urbanístico imputable a nuevos sectores de suelo urbanizable}

\subsubsection{Inciso previo: una posible justificación de la equidistribución de cargas y beneficios entre clases de suelo}

Nuestro Derecho urbanístico ha centrado sus esfuerzos en otorgar un tratamiento jurídico igualitario y rentable a todos los propietarios de suelo que mediante obras de urbanización transforman en ciudad terrenos que tenían la condición originaria de rústicos. A tal efecto, la transformación urbana mediante las obras de urbanización y de reforma interior, eje fundamental del Derecho urbanístico moderno, ha sido complementada con la formulación de complejas técnicas equidistributivas que han procurado ese tratamiento igualitario a todos los propietarios que participan en la actuación de urbanización ${ }^{32}$.

Pero, ¿y qué ha sucedido con el SNU? Centrado el Derecho urbanístico en el cuándo, cómo y dónde de la creación de ciudad, y por tanto en la generación de plusvalías, la regulación de esta clase de suelo ha sido accesoria, reducida a la determinación más o menos cerrada de los suelos que deben ser adscritos a esta categoría, así como

31 Tres ejemplos son destacables. En primer lugar, el art. 79.1 del Decreto Legislativo 1/2000 de Canarias, relativo a los bienes sujetos a los derechos de tanteo y retracto. Según este precepto "los instrumentos de ordenación de los recursos naturales, territorial y urbanística podrán delimitar ámbitos dentro de los cuales las transmisiones onerosas de bienes inmuebles, sean terrenos o edificaciones, estén sujetas al derecho de tanteo y retracto por la Administración Pública, que podrá ejercerlos, en todo caso, en el ámbito de los Espacios Naturales Protegidos, excepto en las zonas de uso tradicional, general y especial de los Parques Rurales. Al delimitar tales ámbitos, el planeamiento establecerá expresamente la finalidad a la que deben destinarse las eventuales adquisiciones, que habrán de ser: b) Realización de programas públicos de protección ambiental, reforestación o de desarrollo agrícola de carácter demostrativo o experimental'. Algo más parca en este sentido es la Ley extremeña 15/2001, cuyo art. 98.1.c) establece que estarán sujetas al derecho de tanteo y, en su caso, de retracto por la Administración de la Comunidad Autónoma de Extremadura, las transmisiones onerosas de los siguientes bienes inmuebles, sean terrenos o edificaciones: “c) Los que tengan la condición de bienes de interés cultural o estén situados en conjuntos de interés ecológico, histórico o artístico".

Con mayor amplitud se pronuncia el art. 182 de la Ley 9/2001 de la Comunidad de Madrid. Según el apartado $1 .^{\circ}$ letra a) de este precepto, están sujetos al derecho de tanteo y, en su caso, retracto, en favor de la Comunidad de Madrid y de los Municipios, las transmisiones onerosas de bienes inmuebles que se realicen: "3..$^{\circ}$ En Espacios Naturales Protegidos; $4 .^{\circ}$ En las zonas de suelo no urbanizable de protección o urbanizable no sectorizado que se delimiten a tal fin por los instrumentos de la ordenación del territorio y el planeamiento urbanístico o, en su defecto, por acuerdo municipal o resolución de la Consejería competente en materia de ordenación urbanística, previa información pública por plazo de veinte días".

32 Tejedor Bielsa, J. (1999): “Propiedad, urbanismo y Estado autonómico”, en Revista de Administración Pública núm. 148, p. 408. 
a los usos, actividades e instalaciones autorizables, cuando así fuera posible y no incompatible con el régimen jurídico urbanístico y sectorial aplicable a estos terrenos ${ }^{33}$. Ahora bien, en ningún caso se ha procurado la implementación de mecanismos de distribución equitativa de las cargas imputables a la prestación de servicios ambientales asumidos por los propietarios del SNU. Desde la lógica de nuestro Derecho urbanístico esta conclusión tendría poco sentido.

El Derecho urbanístico español ha diseñado complicados mecanismos de equidistribución, centrales en todo nuestro sistema jurídico urbanístico ${ }^{34}$, cuya aplicación no ha trascendido del suelo urbano y del suelo urbanizable y, en ningún caso, ha sido prevista ni entre clases de suelo, ni en SNU35. Nuestro ordenamiento no ha dado el paso de generalizar la equidistribución a todas las clases de suelo sencillamente porque en un sistema legal basado en diferentes estatutos de la propiedad no se concibe la posibilidad, ni mucho menos la necesidad, de articular mecanismos de igualación entre quienes no parten de situaciones jurídicas comparables. Desde este punto de vista, habría que decir que la justificación de la desigualdad del régimen jurídico del suelo estriba precisamente en el diferente destino asignado a los distintos terrenos según su clasificación ${ }^{36}$, favoreciendo a aquel propietario que obtiene plusvalías pri-

33 La Exposición de Motivos de la Ley 8/2007, de 28 de mayo, de Suelo, resume con claridad esta idea: “La historia del Derecho urbanístico español contemporáneo se forjó en la segunda mitad del siglo $\mathrm{XIX}$, en un contexto socio-económico de industrialización y urbanización, en torno a dos grandes tipos de operaciones urbanísticas: el ensanche y la reforma interior, la creación de nueva ciudad y el saneamiento y la reforma de la existente. Dicha historia cristalizó a mediados del siglo XX con la primera Ley completa en la materia, de la que sigue siendo tributaria nuestra tradición posterior. En efecto, las grandes instituciones urbanísticas actuales conservan una fuerte inercia respecto de las concebidas entonces: la clasificación del suelo como técnica por excelencia de la que se valen tanto la ordenación como la ejecución urbanísticas, donde la clase de urbanizable es la verdadera protagonista y la del suelo rústico o no urbanizable no merece apenas atención por jugar un papel exclusivamente negativo o residual; la instrumentación de la ordenación mediante un sistema rígido de desagregación sucesiva de planes; la ejecución de dichos planes prácticamente identificada con la urbanización sistemática, que puede ser acometida mediante formas de gestión pública o privada, a través de un conjunto de sistemas de actuación".

34 Parejo Alfonso, L. (1996): “Apuntes para una interpretación del sistema legal urbanístico español en clave histórica”, en Revista Ciudad y Territorio núm. 107-108, pp. 160 a 163, pone de relieve la centralidad del principio de equidistribución vinculado a la ejecución del planeamiento, así como la existencia de un "paralelismo e interdependencia de los estatutos del suelo y de la ejecución” (p. 161). En clave histórica son muy interesantes y trascendentes las reflexiones de Bassols Coma, M. (1996): "Los inicios del Derecho urbanístico en el período del liberalismo moderado y en el sexenio revolucionario (1846-1876): el Ensanche de la ciudad como modelo urbanístico y sistema jurídico", en Revista Ciudad y Territorio núm. 107-108, pp. 19 y ss., con un análisis esclarecedor de la obra de Idelfonso Cerdá y el desarrollo de las primeras técnicas urbanísticas reparcelatorias como solución a la compleja ordenación de la propiedad.

35 La Exposición de Motivos de la Ley 8/1990, de 25 de julio, de reforma del régimen urbanístico y valoraciones del suelo, era bastante clara en este aspecto: "No existe en nuestro Derecho urbanístico vigente (ni en el histórico) un auténtico y pleno derecho a la equidistribución, pues los mecanismos redistributivos ni juegan entre las diversas clases de suelo ni en el seno de cada una de ellas en su totalidad, a excepción del suelo urbanizable programado mediante el instituto del aprovechamiento medio. No reconoce tampoco el sistema que se propone un derecho pleno a la equidistribución, pero extiende su efectividad a los suelos clasificados como urbanos y lo generaliza en las zonas de nueva urbanización (excluidas las de eventual urbanización o no programadas)".

36 Menéndez Rexach, A. (1994): “La propiedad en la nueva Ley del Suelo”, en Revista Derecho Privado y Constitución núm. 3, pp. 96 a 98. 
vadas (por mucho que deba "devolver" a la sociedad parte de las mismas), frente a aquel gravado con deberes repercutidos a la comunidad como un beneficio neto y, en principio, sin contraprestación (los servicios ambientales que prestan los propietarios de $\mathrm{SNU})^{37}$.

Esta misma conclusión es en líneas generales la que se extrae de la jurisprudencia constitucional. La STC 61/1997 [FJ 14.a)] se pronunció acerca del principio de equidistribución con motivo de la impugnación del art. 3.1.b) del TRLS de 1992. Según este precepto, una de las premisas fundamentales del urbanismo español ha sido "impedir la desigual atribución de los beneficios y cargas del planeamiento entre los propietarios afectados e imponer la justa distribución de los mismos". Pues bien, en relación con este precepto la STC 61/1997 afirma lo siguiente: "El art. 3.1 T.R.L.S. no condiciona ni impone al legislador autonómico un determinado modelo territorial y urbanístico, operación ésta que no sería posible en términos competenciales. Su real contenido normativo no es otro que el de establecer los presupuestos o premisas desde los que pretende abordarse el primero de los objetos de la regulación legal -el régimen urbanístico de la propiedad del suelo- (el segundo es la actividad administrativa en materia de urbanismo o 'acción urbanística'). Ha de añadirse que al plasmar tales presupuestos el T.R.L.S. tiene en cuenta los mandatos constitucionales que para el derecho de propiedad del suelo resultan de los arts. 33.2, 47, 128.1 C.E., mandatos sustantivos que obligan a todos los poderes públicos, siendo de notar que el art. 3.1.b) T.R.L.S. ('Impedir la desigual atribución de los beneficios y cargas del planeamiento entre los propietarios afectados e imponer la justa distribución de los mismos'), atiende al elemento teleológico que inspira el art. 149.1.1 C.E., al establecer las condiciones básicas que garantizan la igualdad en el ejercicio de los derechos de los diversos propietarios de suelo frente a los diversos aprovechamientos urbanísticos que el planeamiento -en cuanto técnica a la que es inherente tal desigualdad-pueda asignar a los terrenos incluidos en el ámbito ordenado por aquér".

La referencia que hace la sentencia al efecto igualador "en el ejercicio de los derechos de los diversos propietarios de suelo frente a los diversos aprovechamientos urbanísticos que el planeamiento (... ) pueda asignar a los terrenos incluidos en el ámbito ordenado por aquép', resulta determinante. Pone de relieve que el Tribunal asume la

37 Para Menéndez Rexach, A. (1998): “El nuevo marco legal del urbanismo. La Ley 6/1998, de 13 de abril, de régimen del suelo y valoraciones”, en Documentación Administrativa núm. 252-253, p. 174, la alusión al "elemento teleológico" del art. 149.1.1 de la Constitución, "supone entender implícito en el art. 149.1.1 (y, por tanto, constitucionalizado) el principio de equidistribución y, por tanto, la obligatoriedad de que el legislador arbitre, al servicio de aquél, los instrumentos conducentes al reparto de los beneficios y cargas del planeamiento". A continuación afirma (p. 175) que, aunque existen muchas opciones para garantizar la equidistribución, "el primer problema es si tienen derecho a ella todos los propietarios o si sólo se produce dentro de cada clase de suelo". A tal efecto, Menéndez Rexach afirma que "la segunda ha sido hasta ahora la respuesta de nuestro ordenamiento jurídico", pues como señala la clasificación ha sido el dato jurídico determinante del estatuto de la propiedad, de modo que "la posición jurídica de un propietario de suelo no es igual en todos los casos". Siendo desigual el punto de partida, no tiene por qué ser igual el final del recorrido. En definitiva, esto significa que la equidistribución no puede ser aplicada entre clases de suelo, debido a que la igualación entre los propietarios de distintas clases de suelo no estaría justificada con base en criterios objetivos y razonables. 
concepción de las técnicas equidistributivas para la instrumentación de la igualación de los propietarios de suelo favorecidos por una clasificación que conlleva la atribución de aprovechamiento urbanístico. En otras palabras, la equidistribución, como afirma la sentencia, es un presupuesto ( $\mathrm{y}$ al mismo tiempo un objetivo en cuanto elemento teleológico) desde el que debe emprenderse la regulación legal del régimen urbanístico de la propiedad del suelo. Ahora bien, se ha de prestar atención a que desde el punto de vista constitucional no parecen existir límites definidos sobre "los terrenos incluidos en el ámbito ordenado" a los que se asignen aprovechamientos por el planeamiento.

El siguiente problema al que el Tribunal Constitucional ha prestado atención es si la equidistribución es aplicable a la totalidad de las superficies comprendidas en cada clase de suelo o a una parte de las mismas. Aunque aquí actualmente las soluciones dependen del legislador autonómico, la STC 164/2001 (FJ 10) recuperó esta reflexión cuando analizó la constitucionalidad del art. 5 de la Ley 6/1998, el cual establecía que "las Leyes garantizarán en todo caso el reparto de los beneficios y cargas derivados del planeamiento, entre todos los propietarios afectados por cada actuación urbanística, en proporción a sus aportaciones".

La STC 164/2001 comienza afirmando que "el mandato de equidistribución que contiene esta norma pretende garantizar la igualdad de los propietarios urbanos. Es innegable, entonces, la conexión elemental entre la norma impugnada y el art. 149.1.1 CE”, reiterando así la relación inherente entre el principio de equidistribución y el art. 149.1.1 de la Constitución. Pero lo más destacado a los efectos que ahora nos interesan son las reflexiones que la sentencia hace en relación con los términos "cada actuación urbanística" empleados por el art. 5 de la Ley 6/1998, como marco espacial al que referir la aplicación de las técnicas equidistributivas. En este sentido, la sentencia afirma que "el mandato de equidistribución 'en cada actuación urbanística' es la forma mínima y elemental de garantizar la igualdad entre propietarios. Las desigualdades en beneficios y cargas urbanísticas derivadas del planeamiento son tanto más patentes cuanto mayor es la proximidad y similitud física entre las distintas fincas. Por ello, el art. 5 LRSV identifica cada actuación urbanística concreta como ámbito espacial en el que, en todo caso, debe producirse el reparto de cargas y beneficios. Se trata, por tanto, de una norma mínima de equidistribución reconducible a la competencia de igualación del Estado ex art. 149.1.1 CE. Cada Comunidad Autónoma podrá imponer otros ámbitos y técnicas complementarios de equidistribución. Será decisión de cada Comunidad Autónoma optar, además, por la incorporación de un criterio distributivo en el propio planeamiento; o por imponer la equidistribución sobre amplios espacios de o una misma clase de suelo (incluso entre las fincas integrantes de toda una clase de sue(o)". En definitiva, la sentencia parece dejar abierta la posibilidad de que cada Comunidad Autónoma opte por la aplicación de mecanismos equidistributivos en ámbitos variables, sin que necesariamente sean aplicables en una misma clase de suelo.

Esta interpretación flexible se confirma a la vista de reflexiones posteriores del

152 Tribunal. A continuación, la STC 164/2001 afirma que "en este sentido es claro que el 
art. 5 LRSV no impone un modelo concreto de equidistribución", lo que ratifica que las soluciones equidistributivas quedan abiertas de modo que, por qué no, podrían incluso afectar a distintas clases de suelo. Esta interpretación flexible, encajaría igualmente con los amplios márgenes que la propia sentencia asume y que ya señalamos anteriormente a los efectos de determinar "los terrenos incluidos en el ámbito ordenado" a los que se asignan aprovechamientos por el planeamiento.

Con base en esta interpretación, la posibilidad de que el legislador autonómico establezca ámbitos de equidistribución que afecten a varias clases de suelo parecería viable. No obstante, recordemos que la STC 164/2001 afirma que "las desigualdades en beneficios y cargas urbanísticas derivadas del planeamiento son tanto más patentes cuanto mayor es la proximidad y similitud física entre las distintas fincas". Es decir, esa semejanza es, por tanto, la que justificaría la aplicación de técnicas equidistributivas, algo que se pronunciaría en contra de la posibilidad de aplicar esas mismas técnicas a terrenos cuya clasificación les deparase destinos radicalmente distintos (suelo urbanizable y SNU). Sin embargo, en contra de esta interpretación, cabría citar la nueva regulación de las situaciones básicas del suelo realizada por la Ley 8/2007 y posteriormente por el vigente TRLS de 2008. No en vano, la principal virtualidad de esta nueva categorización del suelo es la "igualación" fáctica en origen de todo el suelo en situación rural, es decir, tanto el SNUEP, como el suelo potencialmente transformable parten según la Ley de una situación básica idéntica ${ }^{38}$. Partiendo de este amplia premisa, no parecería necesario acudir a un subterfugio como el que emplea la legislación urbanística de algunas CCAA, que luego será analizada para aplicar técnicas equidistributivas entre distintas clases de suelo. De hecho, se ha de tener en cuenta que la normativa de aquellas CCAA ha asumido la delimitación de ámbitos de equidistribución que integran suelos clasificados como urbanizables y como no urbanizables, pero la equidistribución no se articula directamente como una redistribución entre suelos de diferentes clases, sino como suelos que aunque pudieran tener la condición originaria de SNU, son calificados como sistemas generales para su adscripción o inclusión en sectores de suelo urbanizable.

Sin embargo, considerando que todos los suelos en situación básica rural son "iguales" en origen, cabría entender que no es extraño al principio de equidistribución la redistribución de cargas y beneficios en ámbitos integrados por suelos que pudieran tener destinos divergentes (creación de ciudad versus prestación de servicios ambientales). Así pues, las técnicas equidistributivas podrían operar como "vehículo" idóneo para relocalizar en sectores de suelo urbanizable, el aprovechamiento urbanístico atribuible a modo de compensación a los propietarios terrenos de SNU que prestan servicios ambientales.

38 Esto es exactamente lo que se desprende del art. 10.3 de la Ley 3/2009, de 17 de junio, de urbanismo de Aragón, en virtud del cual "la determinación de la situación básica de suelo urbanizado a los efectos establecidos en la legislación estatal no está condicionada, en tanto cuestión fáctica y reglada, por la clasificación y calificación urbanística de los terrenos conforme a esta Ley". A esta idea responde también el art. 12.3 en relación con el 14.2 del TRLS de 2008 , en la medida en que considera que los suelos urbanizables susceptibles de transformación se mantienen en situación básica rural hasta que no se produzca la terminación de las actuaciones de urbanización. Es decir, un suelo se mantiene en situación rural, a pesar de ser urbanizable. 
Esta proposición se concretaría en los siguientes criterios básicos: $1 .^{\circ}$ ) Los aprovechamientos atribuibles a los propietarios prestadores de servicios ambientales

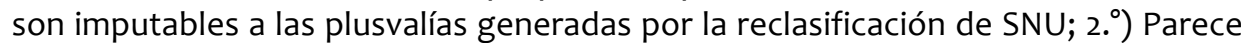
razonable limitar la aplicación de estas técnicas a una superficie de suelo similar a la reclasificada, esto es, fomentar la transferencia de aprovechamientos a superficies idénticas de suelo, en la medida en que ello permite escenificar físicamente y con exactitud la traslación de aprovechamientos entre clases de suelo; $3 .^{\circ}$ ) Los aprovechamientos urbanísticos en ningún caso pueden materializarse en los terrenos que prestan servicios ambientales, pues tales usos serían incompatibles con el destino de esos terrenos; $4^{\circ}$ ) La finalidad de esa compensación es resarcir las cargas derivadas de la prestación de servicios ambientales, así como el mantenimiento de esos terrenos en el destino natural y territorial que es inherente a sus características; $5 .^{\circ}$ ) La aplicación de estos mecanismos a favor de propietarios de SNU debería seguir una gradación, con base en la cual en primer lugar deberían ser favorecidos los propietarios de terrenos en los que la calidad e importancia de los servicios ambientales prestados limite de forma especialmente exigente los usos permitidos y autorizables, para llegar en última instancia a los terrenos cuyos valores podrían no impedir una reclasificación futura39.

Nada de todo esto parece contrario al art. 7 del TRLS de 2008. El primer apartado del art. 7 acoge expresamente el régimen estatutario de la propiedad, considerando que dicho régimen jurídico "resulta de su vinculación a concretos destinos en los términos dispuestos por la legislación sobre ordenación territorial y urbanística". Pues bien, el otorgamiento de aprovechamientos a favor de los propietarios de SNU imputable a las plusvalías generadas en actuaciones de urbanización no supone una "previsión de edificabilidad”, que según el art. 7.2 no se integraría en principio "en el contenido del derecho de propiedad del suelo"; es más, tampoco implica la legitimación de usos "incompatibles con la ordenación territorial y urbanística" en esos terrenos, como así prohíbe el art. 9.1 del TRLS de 2008, pues el otorgamiento de aprovechamientos, insistimos, no es materializable en los terrenos beneficiarios.

Utilizando los mismos moldes dogmáticos que la concepción estatutaria de la propiedad, cabría decir que la normativa que confiere aprovechamientos no materializables a suelos no susceptibles de transformación urbanística conformaría el nuevo

39 Objetivamente esa gradación debería respetar en todo caso el siguiente orden: a) La redistribución de aprovechamientos debería beneficiar en primer lugar a aquellos terrenos que presten servicios ambientales de la más alta calidad y que consecuentemente no gocen de probabilidad alguna de ser reclasificados. Estos terrenos generalmente coincidirán con suelos clasificados como SNUEP y estarán sometidos a algún tipo de protección sectorial que probablemente impedirá casi cualquier uso o aprovechamiento edificatorio y constructivo; b) Terrenos que prestan servicios ambientales de calidad media, cuya posibilidad de reclasificación es baja, al menos mientras no pierdan por procesos naturales los valores que justificaron su clasificación. Estos terrenos coincidirán fundamentalmente con suelos clasificados como SNU protegidos por iniciativa del planificador urbanístico, generalmente no sometidos a una protección sectorial especialmente rigurosa. Ese régimen jurídico suele legitimar ciertos usos y actuaciones edificato154 rias y constructivas que hacen relativamente rentable el uso y aprovechamiento del suelo, lo que permite 
estatuto de la propiedad inmobiliaria de tales terrenos. Estatuto que atribuiría un contenido económico rentable a la propiedad de esos terrenos, legitimando que los propietarios de SNU participen en la ejecución de actuaciones de urbanización en régimen de equitativa distribución de beneficios y cargas [art. 8.1.c) del TRLS de 2008]. Aquí el paralelismo con los sistemas generales de espacios libres y zonas verdes parece obligado y evidente. Quizás por ello, como ya hemos adelantado, las normas autonómicas articulan las transferencias de aprovechamientos que analizamos mediante la calificación de los terrenos prestadores de servicios ambientales como sistemas generales para su adscripción o inclusión en sectores de suelo urbanizable.

Más dudas puede plantear la confrontación de este planteamiento con las previsiones del vigente TRLS de 2008 en materia de valoraciones ${ }^{40}$. En primer lugar, se ha de tener en cuenta que la atribución de aprovechamientos a terrenos clasificados como SNU supondría reconocer un valor al suelo que no atendería exclusivamente a

40 En algún caso incluso podría alegarse una supuesta incompatibilidad de la regulación autonómica con las competencias estatales para establecer el régimen de valoraciones del suelo. Téngase en cuenta a este respecto la STC 14/2007, de 18 de enero (FJ 6), la cual se pronunció sobre la constitucionalidad del art. 19.a) de la Ley del Parlamento Vasco 9/1989, de 17 de noviembre, de Valoración del Suelo, que establecía lo siguiente: “A los únicos efectos de la determinación del valor urbanístico, el aprovechamiento de los terrenos destinados a sistemas generales será: a) En el suelo urbano sujeto a actuaciones aisladas el acordado en el planeamiento urbanístico, o subsidiariamente el 0,2 metros cuadrados de superficie construida o de techo de uso residencial por cada metro cuadrado de suelo". La sentencia mantiene la inconstitucionalidad del precepto por vulnerar competencias estatales: "En el caso concreto objeto de la presente cuestión de inconstitucionalidad, el inciso del artículo 19 a) de la Ley del Parlamento Vasco 9/1989 establece, a los únicos efectos de la determinación del valor urbanístico de los suelos, el aprovechamiento de los terrenos destinados a sistemas generales. Se trata de casos en los que el planeamiento prevé la realización de actuaciones urbanísticas dedicadas a sistemas generales y en la que los propietarios quedan al margen del proceso de urbanización, razón por la que la norma asigna a esos terrenos un determinado valor. Es decir, no se regula la delimitación concreta del aprovechamiento urbanístico a través de un conjunto de figuras y técnicas urbanísticas que permitan hacerlo operativo -cuestión que sin duda encontraría acomodo en la competencia autonómica en materia de urbanismo- sino que lo que se pretende es cuantificar la propiedad inmueble no en términos de aprovechamiento urbanístico sino de compensaciones pecuniarias. De esta forma, la finalidad del precepto, como lo demuestra claramente el objeto del proceso a quo, es el establecimiento de un concreto criterio de valoración de un bien, suelo urbano sin aprovechamiento asignado por el planeamiento, para determinar, utilizando las valoraciones urbanísticas, su valor económico en caso de privación del mismo a través del ejercicio de la potestad expropiatoria por la Administración pública competente para ello. A este respecto, no conviene olvidar que este Tribunal ya descartó en la STC 61/1997, de 20 de marzo, que la valoración correspondiera a la exclusiva competencia de las Comunidades Autónomas debido a las relaciones que dicha valoración tiene con los títulos competenciales estatales derivados de los artículos 149.1.1 y 149.1.18 CE. En la medida en que las valoraciones urbanísticas fijan cuantitativamente el contenido de la propiedad inmueble de cada dueño, y teniendo presente que ya hemos señalado (STC 61/1997, de 20 de marzo, FJ 19) que los criterios de valoración urbanística de los suelos sujetos a planeamiento no pueden quedar desvinculados de los criterios de valoración aplicables a esos mismos suelos cuando quedan afectos a un expediente expropiatorio, la identidad de criterios de valoración constituye un elemento clave para lograr la igualdad de los propietarios de inmuebles urbanos en todo el territorio nacional, puesto que de esta forma se atiende a la garantía del justiprecio y a la previsión de criterios de evaluación uniformes en todo el territorio del Estado. Precisamente por eso, una norma que establece una garantía mínima otorgada por el legislador de un determinado valor urbanístico en defecto de planeamiento entronca tanto con el artículo 149.1.18 CE, en SU vertiente relativa a la fijación de criterios de valoración del suelo a efectos expropiatorios, como con el artículo 149.1.1 CE, en cuanto que la valoración se halla directamente relacionada con las condiciones básicas del derecho de propiedad, lo que determina que, en ambos casos, sea el Estado el competente para establecerla". 
su estado físico actual, aunque sí es cierto que el plusvalor conferido en todo caso consideraría únicamente la condición natural de los mismos a los efectos de otorgarles aquel valor adicional (el correspondiente a los aprovechamientos). Partiendo de la clasificación real del suelo, este planteamiento aparentemente chocaría con lo establecido en la Exposición de Motivos de la Ley 8/2007, cuando afirma como principio que mediatiza las reglas de valoración del suelo que "debe valorarse lo que hay, no lo que el plan dice que puede llegar a haber en un futuro incierto"; dicho de otro modo, el legislador estatal pretende vetar la valoración de expectativas urbanísticas ${ }^{41}$. Como vamos a mostrar a continuación no parece que éste sea nuestro caso, sin perjuicio de que sean otros los inconvenientes jurídicos.

En primer lugar, se ha de tener en cuenta que el art. 23.1.a) del TRLS de 2008 establece que el valor del suelo rural obtenido por aplicación del método de capitalización de rentas puede ser corregido hasta en un 100\% en función de factores como la "renta de posición". Concretamente, según el apartado III del art. 23.1.a) el valor del suelo rural puede ser corregido hasta el doble del valor obtenido según el sistema de capitalización de rentas con base en "factores objetivos de localización, como la accesibilidad a núcleos de población o la ubicación en entornos de singular valor ambiental o paisajístico, cuya aplicación y ponderación habrá de ser justificada en el correspondiente expediente de valoración". Sin embargo, en nuestro caso no parece aplicable este precepto y, por tanto, tampoco el inciso resaltado. Si bien esa "renta de posición" podría corregir el valor de los terrenos en función de criterios como la "ubicación en entornos de singular valor ambiental o paisajístico", no parece que pudiera permitir justificar un mayor valor en virtud del aprovechamiento otorgado a los propietarios de SNU adscritos a nuevos sectores de suelo urbanizable.

Del mismo modo, tampoco parece que sea aplicable a nuestro caso lo establecido por el art. 23.2 del TRLS de 2008, cuando dispone que el suelo en situación básica rural en ningún caso podrá incrementar su valor con base en la consideración de "expectativas derivadas de la asignación de edificabilidades y usos por la ordenación territorial o urbanística que no hayan sido aún plenamente realizados". Como decimos, tampoco este último precepto sería aplicable, ya que la atribución de aprovechamientos no es ninguna expectativa futurible, sino que en la medida en que todos los terrenos se adscriben a ámbitos que participan en actuaciones de urbanización, consecuentemente deberán ser valorados como terrenos en régimen de equidistribución de beneficios y cargas (art. 27 del TRLS de 2008).

41 En el suelo en situación básica rural se abandona el método de comparación porque, como justifica la Exposición de Motivos, muy pocas veces concurren los requisitos necesarios para asegurar su objetividad y la eliminación de la especulación. Es decir, el sistema que se pretende implementar tendrá en cuenta el valor real del suelo rústico, con las inversiones e iniciativas que se hayan producido, pero sin que se retribuyan valores especulativos. Para ello se recurre a la capitalización de rentas. Con este nuevo sistema, suelos susceptibles de ser urbanizados, pero sin urbanización material, podrían valer igual que otros 156 que jamás serán susceptibles de urbanización porque han de ser preservados o protegidos. Esto lógicamente nada tiene que ver con la tasación que hace el mercado de unos y otros terrenos. 
El verdadero inconveniente se plantea precisamente por la aplicación del art. 27. No se puede ocultar que su aplicación podría suponer una consecuente inflación del valor de los terrenos no urbanizables adscritos a los nuevos sectores. Recuérdese en este sentido que este precepto remite la valoración de las aportaciones de los propietarios, salvo acuerdo unánime, al valor de las parcelas finales de resultado. Pues bien, para evitar un encarecimiento artificial del valor de los terrenos cedidos cabría pensar en varias soluciones. En primer lugar, que en los términos del art. 27 del TRLS de 2008 los propietarios acuerden unánimemente cómo deben ser valoradas las aportaciones de suelo de los propietarios de SNU, otorgando un valor específico y proporcionado a esos terrenos en función de su origen y permanencia como suelos no transformados, establecido por comparación con las superficies de suelo urbanizable. En defecto de esa solución convenida, lo que podría ser más que probable, cabría pensar en que el planeamiento urbanístico pudiera establecer coeficientes de equivalencia entre la superficie de los suelos cedidos y la del suelo urbanizable a la que se adscriben, pues lógicamente un metro cuadrado de los terrenos de SNU cedidos no puede valer lo mismo que un metro cuadrado de suelo urbanizable ${ }^{42}$.

A la vista de la doctrina establecida en la STC 14/2007, es discutible si una norma como la mencionada vulneraría o no las competencias estatales. En primer lugar, es dudoso si una norma como la comentada realmente pretende "el establecimiento de un concreto criterio de valoración de un bien (... ) para determinar, utilizando las valoraciones urbanísticas, su valor económico en caso de privación del mismo"; más bien cabría decir que esa norma pretende aplicar las reglas comunes y generales de valoración implementando mecanismos de ponderación ${ }^{43}$. Por otro lado, tampoco cabe señalar que dicha norma establezca "una garantía mínima otorgada por el legislador de un determinado valor urbanístico", sino más bien un criterio de ponderación absolutamente razonable que no garantiza un valor mínimo, sino un valor acorde con la situación fáctica del bien, su destino y por consiguiente su uso.

\subsubsection{La atribución de aprovechamientos a favor de propietarios de suelos no urbanizables como carga redistributiva imputable a los propietarios beneficiados por reclasificaciones}

La articulación de la gestión integral del suelo mediante la imputación directa a los aprovechamientos correspondientes a los propietarios de suelo urbanizable tiene varias formas de manifestación en nuestro ordenamiento que se reconducen en realidad a un único modelo. En todos los casos se articula la atribución de aprovechamientos a suelos con la clasificación de SNU protegido al que se le otorga al mismo tiempo la calificación de terreno dotacional, con el fin de adscribirlo o integrarlo a los nuevos sectores de suelo urbanizable reclasificado.

42 Un buen ejemplo en este sentido es el art. 15.3 de la Ley 10/2004, del suelo no urbanizable de la Comunidad Valenciana, al que luego volveremos a hacer referencia.

43 Haciendo un parangón y salvando las distancias, en términos parecidos a los que prevé la legislación autonómica a los efectos de homogeneizar el aprovechamiento atribuible a los suelos lucrativos en función de su calificación. 
Sin embargo, sí que se pueden distinguir tres formas de manifestación. La primera es la acogida por la legislación valenciana, destacable no tanto por ser pionera en la aplicación de este tipo de mecanismos, como en su perfeccionamiento y su vinculación a un modelo territorial sostenible. En segundo lugar, en la Comunidad de Madrid se han previsto mecanismos similares, pero con una aplicación limitada territorialmente y que no siempre tiene que ver con objetivos de sostenibilidad. Coincide no obstante con el modelo valenciano en que en los dos casos los terrenos cedidos son considerados a los efectos de dar cumplimiento a los estándares urbanísticos de espacios libres y zonas verdes, lo que es criticable pues desvirtúa el sentido de las redes dotacionales, sustituyendo la generación de espacios urbanizados destinados al esparcimiento por la cesión sin transformación de espacios naturales. La tercera manifestación es la establecida en la legislación castellano-leonesa, vía intermedia entre la valenciana y la madrileña.

Empezando con el modelo valenciano, el art. 13.6 de la Ley 4/2004, de 30 de junio, de Ordenación del Territorio y Protección del Paisaje de la Comunidad Valenciana ${ }^{44}$, vincula la posibilidad legal de reclasificar SNU con la cesión a la Administración urbanística de una superficie de SNUEP igual a la reclasificada. Frente a la prohibición de reclasificaciones, la posibilidad legal que pone en marcha este precepto es integrar al SNU en la gestión del suelo, condicionando su reclasificación a una contraprestación adecuada que permita garantizar la sostenibilidad en el desarrollo urbanístico a través de la aplicación de técnicas equidistributivas ${ }^{45}$.

El precepto citado dispone que "toda clasificación de suelo no urbanizable en suelo urbanizable, mediante cualquier medio admitido por la legislación urbanística al margen de la revisión de plan general, supone la cesión gratuita a la administración de suelo no urbanizable protegido, no productivo, con una superficie igual a la reclasificada". En primer lugar, se ha de llamar la atención sobre la aplicación de este precepto únicamente cuando de modificaciones de planeamiento se trate y, por tanto, no en el caso de revisiones ${ }^{46}$. Esta limitación pone de relieve que la finalidad de esta medida es evitar modificaciones puntuales cuyo único objeto sea la reclasificación de

44 La redacción vigente de este precepto corresponde a la otorgada por Ley 14/2005, de 23 de diciembre, de medidas fiscales, de gestión financiera y Administración, y de organización de la Generalitat Valenciana.

45 Serrano López, J. E. (2007): “Medidas compensatorias y cargas adicionales o complementarias. Especial referencia a la obligación de cesión de $\mathrm{m} 2$ x m2 y cuotas de sostenibilidad. La financiación del urbanismo. Los convenios urbanísticos", en Comentarios a la Legislación Urbanística Valenciana, Cizur Menor, Aranzadi, p. 329, afirma que esta medida si bien constituye "una modalidad de participación pública en las plusvalías de la actuación urbanística, constituye propiamente una medida de sostenibilidad territorial. Por cuanto el carácter público del suelo no urbanizable protegido constituye, en principio, la mayor garantía para su conservación". En la misma dirección, González-Varas Ibáñez, S. (2005): Urbanismo y Ordenación del Territorio, Cizur Menor, Aranzadi, p. 555.

46 Además, como es lógico se prevén algunas excepciones que tienen que ver con reclasificaciones singulares promovidas por la Administración pública, sus concesionarios o agentes, que tengan por objeto la implantación de cualquier tipo de equipamiento o actuaciones de interés público y social [art.

158 15.6.e) de la Ley 4/2004], y con el régimen transitorio previsto en la D.Tran. 1. ${ }^{\text {a }}$ del Decreto 67/2006, de 12 de mayo, por el que se aprueba el Reglamento de Ordenación y Gestión Territorial y Urbanística. 
suelo, quebrando el modelo de oferta de suelo establecido al aprobar el planeamiento general.

Del resto de condiciones legales debemos recalcar en primer lugar la consideración de esas cesiones como "dotación de parque público natural” [letra a)] ${ }^{47}$, cuya satisfacción se debe llevar a cabo en terrenos en los que concurran las circunstancias establecidas y en el orden de preferencia previsto en el art. 21 del Decreto 67/2006, de 12 de mayo, por el que se aprueba el Reglamento de Ordenación y Gestión Territorial y Urbanística ${ }^{48}$. El orden de preferencia del art. 21.1 es realmente taxativo, pues como señala el apartado $2 .^{\circ}$ del art. 21, no cabe la cesión de suelos en una categoría inferior existiendo suelos disponibles de una categoría preferente ${ }^{49}$. Además, es interesante que el art. 13.6.c) de la Ley 4/2004 establezca que "el planeamiento podrá delimitar áreas en las que se materialice la cesión por su interés público local, o pertenecientes a entornos de los espacios naturales protegidos" ${ }^{50}$, lo que debería servir para direccionar las cesiones hacia los terrenos con mayor vulnerabilidad y presión exterior.

47 Se ha de llamar la atención acerca de esta cuestión, pues el art. 13.6.a) de la Ley 4/2004 dispone que esas dotaciones de parque público natural computarán para satisfacer los estándares urbanísticos previstos en el art. 8.1.c) de la misma Ley sobre zonas verdes y parques públicos. En la misma dirección el art. 15.3 de la Ley 10/2004, de 9 de diciembre, del suelo no urbanizable de la Comunidad Valenciana. Según este precepto, "sin perjuicio de las reservas de suelo para parque público exigibles en la legislación urbanística, podrán incluirse en la red primaria, con la consideración de parque público natural, suelos clasificados como no urbanizables, en cualquiera de sus categorías, que, pese a reunir algún tipo de valor paisajístico o medioambiental, posean características especiales que los haga especialmente aptos para el esparcimiento ciudadano. Estos parques públicos estarán adscritos a los distintos sectores de suelo urbanizable, siéndoles de aplicación la legislación urbanística. La normativa urbanística del plan establecerá para estos parques las condiciones que compatibilicen su uso con la protección de los valores existentes".

48 Resumidamente el orden de preferencia es el siguiente: $\left.1^{\circ}{ }^{\circ}\right)$ Que estén formal y expresamente declarados como suelo protegido en aplicación de la legislación sectorial de espacios naturales protegidos, incluyendo los pertenecientes a la Red Natura 2000 y zonas húmedas catalogadas. 2. ${ }^{\circ}$ ) Que ya esté incoado un procedimiento para la declaración de los terrenos como SNUEP en virtud de la legislación en materia de espacios naturales del aparado anterior, siempre y cuando tales terrenos estén sujetos a un régimen de protección cautelar y hayan sido objeto de informe favorable de la Conselleria competente en materia de territorio. $3 .^{\circ}$ ) Suelos pertenecientes a los entornos de protección, de amortiguación de impactos, preparques, corredores biológicos y otros suelos vinculados a las figuras de protección antes señaladas, siempre que fuesen suelos no urbanizables de protección especial, y además hayan sido objeto de un informe favorable del órgano correspondiente de la Conselleria competente en materia de territorio u órgano que lo sustituya. $4 .^{\circ}$ ) Que los terrenos estén formal y expresamente clasificados como suelo no urbanizable protegido por el planeamiento municipal de conformidad con la pertinente evaluación ambiental.

49 En caso de que en el término municipal en cuestión no sea posible la cesión de los suelos señalados, cabe tanto su localización en otros términos municipales (art. 21.3 del Decreto 67/2006), como su sustitución por su equivalente en dinero con obligación de ser destinado a programas y proyectos para la sostenibilidad y la calidad de vida [art. 13.6.d) de la Ley 4/2004, art. 47.3 de la Ley 16/2005 y 24 del Decreto 67/2006].

50 El art. 52.2.b) de la Ley 16/2005 de la Comunidad Valenciana añade que necesariamente el Plan General deberá prever los siguientes elementos de la red primaria: “Áreas destinadas a parques públicos naturales en las que deba materializarse la cesión gratuita a la Administración de una superficie equivalente de suelo no urbanizable protegido, a las que se refiere el artículo 13.6 de la Ley 4/2004, de 30 de junio, de Ordenación del Territorio y Protección del Paisaje, salvo que las directrices definitorias de la estrategia de evolución urbana y de ocupación del territorio excluyan nuevas clasificaciones de suelo urbanizable. Estos parques públicos naturales deberán estar clasificados como suelo no urbanizable". 
Un problema que no ataja la regulación valenciana es el no establecimiento de límites aplicables sobre los suelos que pueden ser susceptibles de reclasificación. Es decir, la normativa autonómica no condiciona la reclasificación a la previa corroboración y documentación de la inexistencia o pérdida de valores de los terrenos a reclasificar. Esto significa, en definitiva, que la cesión de terrenos protegidos en mayor o menor intensidad se ve compensada con la reclasificación de terrenos clasificados como SNU que no necesariamente tienen por qué estar degradados, pero que no están "oficialmente" protegidos o en vías de estarlo. Es más, satisfecha la cesión de los terrenos situados en los primeros escalones del art. 21 del Decreto 67/2006, nada impide que la reclasificación pudiera afectar a alguno de los terrenos localizables en los últimos apartados de ese precepto. Para evitar esta paradójica situación, a pesar del silencio reglamentario, parece evidente que deberán aplicarse también en estos casos límites similares a los que viene exigiendo la jurisprudencia del Tribunal Supremo ${ }^{51}$.

Otro inconveniente que cabe destacar es que este mecanismo, por sí mismo, no constituye un freno a la generación de nueva oferta de suelo. En fin, el riesgo que $a$ priori se corre con este sistema es evidente: siempre que haya suelo protegido en el término municipal o en otros (art. 21.3 del Decreto 67/2006), parecería posible poder reclasificar suelo. Ahora bien, esta afirmación debe ser condicionada por los límites a la clasificación de suelo urbanizable previstos en los arts. 12.1, 44.1.c) y 45.1.c) y d) de la Ley 16/2005, de 30 de diciembre, Urbanística Valenciana, en función de las directrices de sostenibilidad establecidas en el planeamiento ${ }^{52}$. En otras palabras, la reclasifi-

51 Sobre esta cuestión véase, Agudo González (2010a: in toto). Junto al SNUEP que de forma reglada el planificador debe clasificar como SNU, en la medida en que el legislador, el planificador o una decisión administrativa sectorial o territorial prevalente predetermina o impone dicha clasificación urbanística, el planificador urbanístico también puede proteger por propia iniciativa terrenos en los que identifique valores merecedores de protección en el marco de los considerados por el legislador urbanístico. A este segundo grupo de terrenos es al que afecta la doctrina jurisprudencial a la que aludimos. Pues bien, según las SSTS de 17 de febrero de 2003 (Az. 2891), 25 de octubre de 2006 (Az. 764 de 2007) o de 3 de julio de 2007 (Az. 3753), entre otras: $\left.1^{\circ}{ }^{\circ}\right)$ La clasificación de un terreno como SNU protegido con base en los valores reconocidos por el propio planificador urbanístico, esto es, no condicionada por una decisión administrativa previa y vinculante o por un mandato legal que exija la clasificación del suelo como SNUEP, elimina las facultades discrecionales del planificador para modificar el régimen jurídico de esos mismos terrenos mediante su reclasificación; y $2^{\circ} .^{\circ}$ La reclasificación sólo será conforme a Derecho si se demuestra de forma específica y reforzada, esto es, con base en datos científico-técnicos, la degradación de esos espacios, o dicho de otra manera, que los valores que justificaron la clasificación del suelo como SNU protegido, han desaparecido.

52 En primer lugar, el art. 12.1 establece que "el planeamiento clasificará como suelo urbanizable los terrenos que pretenda incorporar al proceso de urbanización, a medida que el desarrollo de la red primaria de dotaciones y el grado de definición de la ordenación estructural permita integrarlos en dicho proceso dentro de un modelo territorial sostenible y coherente". Por su parte, el art. 44.1.c) dispone que las directrices de sostenibilidad del Plan General establecerán "los criterios a tener en cuenta para la incorporación de nuevos terrenos al proceso de urbanización”. Finalmente, el art. 45.1.c) establece que las directrices definitorias de la estrategia de evolución urbana y ocupación del territorio fijarán criterios y objetivos que tengan por finalidad la consecución de la sostenibilidad del Municipio y, en concreto, respecto de la utilización racional del suelo, "establecerán los criterios para dirimir la posible incorporación de nuevos terrenos al proceso de urbanización y las necesidades de ampliación de la red primaria que eso exija cuando se trate de aumentar la superficie de suelo urbanizable en principio prevista por el plan". La letra d) de este último precepto añade que las directrices "establecerán los criterios para dirimir la posible incorpora- 
cación de SNU no sólo depende de la existencia de suelo protegido, sino también del cumplimiento de las citadas directrices ${ }^{53}$.

Pasando al examen de los términos en que opera este mecanismo, debemos insistir en que implica el reconocimiento de un contenido de naturaleza urbanística de suelo clasificado como SNU, pero que se incorpora a una actuación de urbanización como suelo dotacional. Asimismo, como sucede respecto de cualquier suelo dotacional, la atribución de aprovechamientos se hace proporcionalmente a las aportaciones de cada propietario y a modo de compensación por la posterior cesión de tales terrenos. Dicho de otro modo, el propietario de SNU patrimonializa un aprovechamiento en su condición de propietario de terrenos que, como todos los terrenos dotacionales, son aportados a una actuación de urbanización. Recuérdese que los terrenos son cedidos como "dotaciones de parque público natural”, de modo que nos encontraríamos ante una manifestación más del deber legal previsto en el art. 16.1.a) del TRLS de 2008 , relativo a la "entrega" de suelo reservado para espacios libres y zonas verdes, cuyos propietarios son satisfechos como el resto de propietarios de suelos dotacionales. Consecuentemente, el aprovechamiento atribuido a esos propietarios se detrae del aprovechamiento lucrativo del ámbito de actuación, pero en ningún caso se materializa en tales terrenos. Estas conclusiones se confirman con base en el art. 20.4 del Decreto 67/2006, el cual establece que "los propietarios de estos suelos (de los terrenos adquiridos y cedidos, se entiende) podrán participar en la reparcelación como titulares de suelos aportados a los que se aplicará el correspondiente coeficiente de ponderación de valor de acuerdo con lo dispuesto en la legislación estatal sobre régimen del suelo y valoraciones" ${ }^{54}$.

ción de nuevos terrenos al proceso de urbanización y las necesidades de ampliación de la Red Primaria que ello exija cuando se trate de aumentar la superficie de suelo urbanizable en principio prevista por el Plan".

53 Por otro lado, ambos criterios deben ser complementados con los límites derivados de la aplicación del Fondo para la Equidad Territorial creado por Ley 4/2004, de 30 de junio, de Ordenación del Territorio y Protección del Paisaje de la Comunidad Valenciana, cuya finalidad es financiar proyectos para la sostenibilidad y la calidad de vida con las cuotas de sostenibilidad derivadas de la gestión urbanística o de la implantación de infraestructuras, pero también de actividades en SNU. La Ley valenciana 4/2004 establece un sistema de cuotas determinadas en función del grado de cumplimiento de los denominados umbrales de sostenibilidad. Pues bien, vinculado con estos umbrales, el art. 83 de la Ley valenciana establece la definición de "cuotas de sostenibilidad", entendiendo por tales, "las aportaciones derivadas de las acciones consumidoras de recursos o emisoras de contaminantes a las acciones para la sostenibilidad y la calidad de vida, conforme a lo establecido en la presente Ley". Esas cuotas son fijadas en función de tres conceptos: a) El art. 84 establece las cuotas de sostenibilidad derivadas de la gestión urbanística; b) El art. 85 se refiere a las cuotas de sostenibilidad derivadas de actuaciones en suelo no urbanizable; y c) El art. 87 prevé las cuotas de sostenibilidad derivadas de la implantación de infraestructuras.

54 Con anterioridad al Decreto 67/2006, ya el art. 15.3 de la Ley 10/2004, del suelo no urbanizable de la Comunidad Valenciana, estableció que los terrenos clasificados como SNU incluidos en la red primaria de dotaciones con la consideración de parque público natural, "estarán adscritos a los distintos sectores de suelo urbanizable", añadiendo que "el plan podrá establecer justificadamente un coeficiente de equivalencia entre la superficie de estos suelos y la del suelo urbanizable a la que se adscriben, a efectos de reparto de beneficios y cargas". En este sentido, también el art. 58.5 de la Ley 16/2005, según el cual “podrán también delimitarse unidades de ejecución discontinuas para la obtención de suelos con destino a parques públicos naturales como consecuencia de una reclasificación de suelo, cuando así proceda en aplicación de la Ley 4/2004, de 30 de junio, de Ordenación del Territorio y Protección del Paisaje. Estos suelos para parques públicos naturales serán clasificados como suelo no urbanizable, integrándose como tales en el área de reparto 
En otras CCAA como Madrid la formalización de mecanismos similares se ha limitado a terrenos clasificados como SNUEP que formen parte de espacios naturales protegidos. Es decir, a diferencia de la legislación valenciana, no se prevé la posibilidad de aplicar estos mecanismos equidistributivos a otros suelos protegidos ${ }^{55}$. En lo que sí coinciden todas las CCAA es en que también en este segundo grupo esos terrenos son adscritos a sectores mediante su integración en las redes de sistemas generales. En otras palabras, aunque no se establezca expresamente, del mismo modo que en el caso valenciano, esa forma de actuar permitiría imputar aprovechamientos a tales terrenos vinculados a una previa reclasificación; en concreto, la obtención de esos suelos se podría articular mediante su adscripción a nuevos sectores de suelo urbanizable para que computen como redes públicas. Ahora bien, a diferencia de lo que sucede en la Comunidad Valenciana, ni se establece una obligación de adscripción de terrenos prestadores de servicios ambientales siempre que se apruebe una reclasificación de suelo, ni lógicamente se establece ningún límite cuantitativo. Es decir, este mecanismo no se prevé como un instrumento para la sostenibilidad, sino para el cumplimiento de los estándares urbanísticos.

Antes de pasar al repaso de la normativa madrileña, es interesante poner de relieve que al contrario de lo que sucede en la Comunidad de Madrid, en otras CCAA se ha prohibido expresamente esta posibilidad, precisamente por la tergiversación a la que aludimos a la hora de dar satisfacción a los estándares urbanísticos. Así, por ejemplo, el art. 40.1.b).1. ${ }^{\circ}$ de la Ley 3/2009 de Aragón, en la que se afirma que el Plan Gene-

resultante con los correspondientes coeficientes de ponderación de valor". Redunda igualmente en esta idea el art. 73.3.f) de la misma Ley 16/2005, cuando dispone que "los Planes Parciales modificativos que incorporen al proceso de urbanización terrenos que, conforme al Plan General, no tuviesen la clasificación formal de suelo urbanizable se ajustarán a las siguientes reglas: f) Con cargo a la actuación integrada, además de las cesiones legalmente exigibles, procederá la cesión de suelo no urbanizable protegido en la cuantía establecida en el artículo 13.6 de la Ley de Ordenación del Territorio y Protección del Paisaje, a favor de la administración pública que reglamentariamente se establezca. Los terrenos objeto de esta cesión podrán ser obtenidos en cualquiera de las formas previstas para la obtención de los elementos de la red primaria adscrita".

Finalmente, el art. 169.3.e) de la Ley 16/2005, relativo a la reparcelación forzosa, señala que ésta tiene por objeto, si procede, "materializar el cumplimiento de la carga de obtener suelo no urbanizable protegido a que se refiere la Ley 4/2004, de 30 de junio, de la Generalitat de Ordenación del Territorio y Protección del Paisaje, en el caso en que la reparcelación se produzca en ejecución de un instrumento de planeamiento que implique el cambio de clasificación de suelo no urbanizable a urbanizable, estableciendo los oportunos coeficientes de ponderación de valor entre el suelo no urbanizable y el urbanizable a que se adscribe, de acuerdo con la Ley 6/1998, de 13 de abril, de Régimen del Suelo y Valoraciones".

55 En la Comunidad de Baleares se ha previsto un supuesto en el que la adscripción de los terrenos a sistemas generales no se limita al SNUEP adscrito a espacios naturales protegidos, sino también a todo el suelo rústico. Ahora bien, la medida tiene una perspectiva territorial parcial. Concretamente, la D.Ad. 2. ${ }^{a}$ de la Ley $4 / 2008$, de 14 de mayo, de medidas urgentes para un desarrollo territorial sostenible, relativa al cumplimiento de dotaciones mínimas, dispone que "los Municipios de Andratx y de Santa Eulàlia del Riu, dado que quedan afectados significativamente en los estándares de zonas verdes por las disposiciones de esta Ley, podrán delimitar zonas verdes equivalentes en el suelo rústico como parte del sistema general de espacios libres públicos y a los efectos del cumplimiento de las dotaciones mínimas que para este uso prevé la legislación vigente. Este uso deberá ser compatible con el régimen de protección del suelo en que se ubique y en ningún caso supondrá un cambio en la clasificación del suelo ni en su calificación". 
ral deberá comprender las reservas de terrenos para "espacios libres públicos destinados a parques y áreas de ocio, expansión y recreo", "sin incluir en el cómputo espacios naturales protegidos, grandes zonas verdes suburbanas ni dotaciones locales". La misma solución se reitera en el art. 39.2 de la Ley 2/2001 de Cantabria, así como el art. 59.2.a).4. ${ }^{\circ}$ y 5. ${ }^{\circ}$ del Decreto Legislativo 1/2004 de Asturias.

Al contrario que las Leyes citadas, el art. 36.2.b).1. ${ }^{\circ}$ de la Ley 9/2001 de la Comunidad de Madrid prevé sin embargo que las redes de equipamientos comprenderán: "Red de zonas verdes y espacios libres, tales como espacios protegidos regionales, parques municipales y urbanos, jardines y plazas" 56 . La primera cuestión importante que se deriva de la Ley madrileña ${ }^{57}$ es si los terrenos adscritos a sistemas generales realmente se ceden y se afectan al dominio público o si, por el contrario, mantienen su titularidad originaria, pero incorporados a las redes generales. En fin, la idea es evitar un subterfugio que puede distorsionar la funcionalidad de las dotaciones urbanísticas y el cumplimiento efectivo de los deberes de cesión de los propietarios de suelo: dar cumplimiento a las reservas de suelo dotacional con terrenos privados.

La jurisprudencia que ha tenido ocasión de pronunciarse sobre las normas comentadas sí que alude con rotundidad a que la calificación de SNU como sistemas generales tiene como finalidad la obtención del suelo, de lo que parece se ha de derivar la publificación de los terrenos. Así, al menos, se deduce de dos sentencias del TSJ de la Comunidad de Madrid, las SSTSJ de 21 de diciembre de 2006 (Rec. 341/2002; Pte.- Martín Corredera) y de 21 de noviembre de 2007 (Rec.- 3258/2004; Pte.- Rosas

56 La STSJ de Madrid, de 21 de diciembre de 2006 (Rec. 341/2002; Pte.- Martín Corredera) se pronunció acerca de la impugnación del acuerdo de la Comisión de Urbanismo de Madrid, de 26 de junio de 2002, por el que se denegó la aprobación definitiva de la modificación puntual de las NNSS de Valdemaqueda consistente en calificar como Sistema General de Espacio Libres, un ámbito de aproximadamente 800 Hectáreas clasificado como SNUEP. A los efectos que ahora nos interesan, la sentencia afirma lo siguiente: "El ordenamiento urbanístico no prevé el establecimiento de sistemas generales cuya única finalidad es la de imponer medidas de protección del paisaje, cuando esa finalidad ya queda garantizada mediante la clasificación del suelo como no urbanizable especialmente protegido". Sin embargo, el precepto citado parece que podría permitir fundamentar exactamente lo contrario, eso sí, como complemento de la clasificación del suelo como SNUEP.

Sin embargo, indirectamente se admite una solución contraria en la STS de 2 de abril de 2007 (Rec.7246/2003; Pte.- Peces Morate), en la que se resuelve el recurso de casación interpuesto originalmente contra el acuerdo de aprobación definitiva de la Revisión del Plan General de Ordenación Urbana de Madrid adoptado por el Consejo de Gobierno de la Comunidad de Madrid en su sesión del día 17 de abril de 1997, en lo que se refiere al punto b) del apartado segundo B), por el que se desclasifica como suelo urbanizable no programado el Sector 04.13 del Plan General de Madrid, y se ordena que se clasifique como no urbanizable o como sistema general de espacios libres. Pues bien, al hilo de los argumentos del Tribunal acerca del alcance de las facultades de control de que goza la Comunidad Autónoma al momento de la aprobación definitiva de los planes urbanísticos, se confirma la actuación autonómica señalando que "afectaba a intereses ambientales no sólo del municipio de Madrid sino a la estructura del sistema de espacios libres de la zona oeste de la Comunidad de Madrid, de modo que no se ha conculcado la autonomía municipal para gestionar los intereses propios ni la doctrina jurisprudencial que avala el control del planeamiento municipal por la Comunidad Autónoma cuando sus determinaciones inciden en aspectos de interés supralocap'.

57 Lo que se debe hacer extensible a la la D.Ad. $2 .^{\text {a }}$ de la Ley balear 4/2008, de 14 de mayo, de medidas urgentes para un desarrollo territorial sostenible, antes comentada. 
Carrión). En ambas sentencias, con conclusiones bastante distintas por otro lado, se afirma que la finalidad de esa calificación del suelo no es otra que "la adquisición de los terrenos en favor del municipio de Valdemaqueda para satisfacer sus intereses de desarrollo económico" ${ }^{58}$, o bien que "la clasificación y calificación referida no ha privado a la recurrente de la propiedad de sus parcelas, siendo cuando se ejecute el planeamiento el momento en que deberá plantearse la cuestión, ahora extemporánea por anticipada, de si su obtención por el Ayuntamiento ha sido, o no, debidamente compensada" 59 .

Con posterioridad a la Ley madrileña, y una vez en vigor la Ley 8/2007, en Castilla y León se ha previsto un modelo intermedio entre el valenciano y el madrileño. Cabe destacar en primer lugar la modificación de los arts. 38 y 41 de la Ley 5/1999 de Castilla y León por Ley 4/2008, de 15 de septiembre, de medidas sobre urbanismo y suelo, aprobada para adaptar la legislación castellano-leonesa a la Ley 8/2007. Pues bien, lo más relevante es el radical cambio de orientación que ha imprimido la nueva Ley en los aspectos que ahora nos interesan.

La redacción original del art. 41.c).3. ${ }^{\circ}$ de la Ley castellano-leonesa disponía, en la línea de las Leyes de Cantabria, Asturias y Aragón, que los estándares relativos a los sistemas generales de espacios libres públicos debían cumplirse "sin incluir en el cómputo sistemas locales ni espacios naturales". La nueva redacción otorgada por Ley $4 / 2008$ ha añadido un nuevo apartado $5 .^{\circ}$ a la letra c) del art. 41, en el que se establece que el Plan General establecerá las determinaciones de ordenación general y, en concreto, las relativas al "sistema general de espacios protegidos" 60 . Esta nueva previsión legal es coherente con la modificación del art. 38 de la Ley 5/1999, en la que se ha introducido una nueva letra e) al apartado $1 .^{\circ}$ del precepto, en virtud del cual el planeamiento urbanístico señalará reservas de suelo para dotaciones urbanísticas y específicamente la siguiente: “e) Espacios protegidos: sistema de espacios protegidos por la

58 En el caso de la STSJ de 21 de diciembre de 2006 (Rec. 341/2002; Pte.- Martín Corredera), en la que se resuelve el recurso contencioso-administrativo interpuesto contra el acuerdo de la Comisión de Urbanismo de 26 de junio de 2002, por el que se denegó la aprobación definitiva de la modificación puntual de las Normas Subsidiarias de Valdemaqueda consistente en calificar como Sistema General de Espacio Libres, un ámbito de aproximadamente 800 hectáreas, actualmente clasificado como Suelo No Urbanizable Especialmente Protegido por su Interés Forestal y Paisajístico, en la medida en que dicha alteración de planeamiento debió articularse como una revisión.

59 En el supuesto de la STSJ de de 21 de noviembre de 2007 (Rec.- 3258/2004; Pte.- Rosas Carrión) por la que se resuelve el recurso interpuesto contra el Acuerdo del Consejo de Gobierno de la Comunidad de Madrid de 17 de junio de 2004, de aprobación definitiva de la Revisión del Plan General de Ordenación Urbana de Getafe, en virtud del cual se otorgó la clasificación de SNUEP-3 a las fincas denominadas "Cerro de Los Ángeles-Laguna de Perales", al tiempo que se las calificaba como "Red Pública General de Zonas Verdes y Espacios Libres".

60 La nueva redacción del art. 13.2 de la Ley castellano-leonesa dispone que "podrán clasificarse como suelo urbanizable terrenos que, cumpliendo requisitos para ser clasificados como suelo rústico conforme a la legislación sectorial o al artículo 15, sea conveniente calificar como sistema general de espacios protegidos a efectos de su obtención para el uso público. Estos terrenos no podrán ser urbanizados. Los 164 efectos de la clasificación se limitarán a las actuaciones necesarias para su obtención y en su caso recuperación y adecuación, en el marco de la normativa que los proteja". 
normativa sectorial que sea conveniente integrar en la red de dotaciones urbanísticas". En definitiva, también en este caso la reserva de espacios protegidos tiene como finalidad adscribir terrenos que prestan servicios ambientales a sistemas generales a los efectos de "su obtención y en su caso recuperación y adecuación, en el marco de la normativa que los proteja” (art. 13.2 del Ley 5/1999 según la nueva redacción otorgada por Ley 4/2008). Ahora bien, a diferencia de la normativa valenciana y madrileña, estas dotaciones no son computables como parte de la red de espacios libres y zonas verdes, sino que conforman un tipo dotacional específico.

En términos parecidos a la legislación valenciana, lo trascendente tanto en el caso de la legislación madrileña, como en el castellano-leonés, es la posible imputación de aprovechamiento urbanístico a los suelos clasificados como SNU calificados como sistema general adscritos o incluidos en sectores de suelo urbanizable. Efectivamente, sin perjuicio de su obtención por los mecanismos alternativos que prevé la legislación de suelo, en los casos mencionados los terrenos adscritos a sistemas generales generan aprovechamiento ${ }^{61}$, aunque sea un aprovechamiento no materializable en ese suelo ${ }^{62}$. De hecho, si los terrenos destinados a sistemas generales se encuentran integrados en áreas de reparto, aparte de estar adscritos o incluidos en ámbitos de gestión urbanística, es evidente que tales terrenos participan en el cálculo del aprovechamiento urbanístico. Si no fuera así, a los propietarios afectados se les compensaría detrayendo parte del aprovechamiento de los propietarios del suelo del ámbito al que se adscriben o incluyen los terrenos. En consecuencia, y en virtud del correspondiente procedimiento redistributivo llevado a cabo en cada ámbito de gestión, los propietarios de terrenos afectos a sistemas generales cederán estos terrenos, siendo compensados con superficies con aprovechamiento lucrativo en el ámbito correspondiente. Esto evidentemente significa que el planeamiento debe crear ámbitos de actuación en los que se contemple el alojamiento del aprovechamiento que corresponde al suelo destinado a sistemas generales.

\section{BIBLIOGRAFÍA}

Agudo González, J. (2004): “Desafectación y compensación de terrenos dotacionales, como premisa para su permuta por obra futura”, en Revista de Derecho Urbanístico y del Medio Ambiente, núm. 213.

61 López Pellicer, J. A. (2000): “Sobre el nuevo régimen de valoración del suelo”, en Revista de Derecho Urbanístico y del Medio Ambiente núm. 177, p. 145.

62 Como pone de manifiesto González-Berenguer Urrutia, J. L. (1993): “El suelo para sistemas generales no se cede gratuitamente jamás (I)", en Revista de Derecho Urbanístico y del Medio Ambiente núm. 135, pp. 75 y ss., el suelo afectado por sistemas generales tiene aprovechamiento, a pesar de que el art. 51 del Reglamento de Gestión Urbanística (hoy derogado) dijera que estos terrenos tienen "aprovechamiento cero". Aprovechamiento que se traduce o en un justiprecio o en un derecho a edificar emplazable en lugar distinto al de la propiedad original adscrita a sistemas generales. De la misma opinión, García Gómez de Mercado, F. (2001): El justiprecio en la expropiación forzosa, Granada, Comares, p. 190, y Jiménez de Cisneros Cid, F. J. y Agudo González, J. (2004): Expropiación y grandes infraestructuras, Madrid, Montecorvo, pp. 93 y 94. 
Agudo González, J. (2007): “Paisaje, gestión del territorio y patrimonio histórico”, en Revista Patrimonio Cultural y Derecho, núm. 11.

Agudo González, J. (2010a): “Mecanismos jurídicos para la limitación de la oferta de suelo", en Revista de Derecho Urbanístico y Medio Ambiente, núm. 258.

Agudo González, J. (2010b): “La 'intercambialidad' del suelo urbanizable y no urbanizable", en Revista Aragonesa de Administración Pública, núm. 36.

Bassols Coma, M. (1996): “Los inicios del Derecho urbanístico en el período del liberalismo moderado y en el sexenio revolucionario (1846-1876): el Ensanche de la ciudad como modelo urbanístico y sistema jurídico", en Revista Ciudad y Territorio, núm. 107-108.

Blanquer Criado, D. (2007): Los Patrimonios Públicos del Suelo, Tirant lo Blanch, Valencia.

Delgado Piqueras, F. (2008): “Novedades del régimen básico de los patrimonios públicos de suelo", en Revista de Derecho Urbanístico y del Medio Ambiente, núm. 240.

Fernández Rodríguez, T. R. (1991): Manual de Derecho Urbanístico, Madrid, El Consultor. García Gómez de Mercado, F. (2001): El justiprecio en la expropiación forzosa, Granada, Comares.

González-Berenguer Urrutia, J. L. (1993): “El suelo para sistemas generales no se cede gratuitamente jamás (I)", en Revista de Derecho Urbanístico y del Medio Ambiente, núm. 135 .

Gómez-Limón García, J. (coord.) (2008): Plan de Acción para los espacios naturales protegidos del Estado español. Planificar para gestionar los espacios naturales protegidos, EUROPARC-España, 2008.

González-Varas Ibáñez, S. (2005): “La Gestión Territorial”, en Revista de Administración Pública, núm. 166.

González-Varas Ibáñez, S. (2005): Urbanismo y Ordenación del Territorio, Cizur Menor, Aranzadi.

Lasagabaster Herrarte, I. y Lazcano Brotóns, I. (2004): “Protección del paisaje, ordenación del territorio y espacios naturales protegidos", en Revista Vasca de Administración Pública, núm. 70.

Lobato Gómez, J. M. (1989): Propiedad privada del suelo y derecho a edificar, Madrid, Montecorvo.

López Pellicer, J. A. (2000): "Sobre el nuevo régimen de valoración del suelo", en Revista de Derecho Urbanístico y del Medio Ambiente núm. 177.

Mata Olmo, R. (2006): “Un concepto de paisaje para la gestión sostenible del territorio", en Mata Olmo, R. y Tarroja Coscuela, A. (coords.), El paisaje y la gestión del territorio. Criterios paisajísticos en la ordenación del territorio y el urbanismo, Barcelona, Diputación de Barcelona y CUIMPB.

Martín Hernández, P. (2006): “El patrimonio municipal del suelo: su evolución normativa”, en Revista de Derecho Urbanístico y del Medio Ambiente, núm. 225.

Menéndez Rexach, A. (1994): "La propiedad en la nueva Ley del Suelo", en Revista Derecho Privado y Constitución núm. 3.

Menéndez Rexach, A. (1998): “El nuevo marco legal del urbanismo. La Ley 6/1998, de 13 de abril, de régimen del suelo y valoraciones", en Documentación Administra166 tiva núm. 252-253. 
Menéndez Rexach, A. (2007): “Artículos 33 y 34”, en Sánchez Goyanes, E. (dir.), Ley de Suelo. Comentario sistemático de la Ley 8/2007, de 28 de mayo, de Suelo, Madrid, La Ley.

Jiménez de Cisneros Cid, F. J. y Agudo González, J. (2004): Expropiación y grandes infraestructuras, Madrid, Montecorvo.

Parada Vázquez, R. (1988): Derecho Administrativo. Bienes públicos y urbanismo, Madrid, Marcial Pons.

Parejo Alfonso, L. (1995): “La propiedad urbana”, en BARNÉS Vázquez, J. (coord.), Propiedad, expropiación y responsabilidad. La garantía indemnizatoria en el Derecho europeo y comparado, Madrid, Civitas.

Parejo Alfonso, L. (1996): “Apuntes para una interpretación del sistema legal urbanístico español en clave histórica”, en Revista Ciudad y Territorio núm. 107-108.

Parejo Alfonso, L. y Roger Fernández, G. (2007): Comentarios a la Ley de Suelo (Ley 8/2007, de 28 de mayo), Madrid, lustel.

Quintana López, T. (2004): “La regulación de los Patrimonios Públicos del Suelo como fuente de controversia", en Revista Española de Derecho Administrativo núm. 121.

Serrano López, J. E. (2007): “Medidas compensatorias y cargas adicionales o complementarias. Especial referencia a la obligación de cesión de $\mathrm{m} 2$ x m2 y cuotas de sostenibilidad. La financiación del urbanismo. Los convenios urbanísticos", en Comentarios a la Legislación Urbanística Valenciana, Cizur Menor, Aranzadi.

Tarroja Coscuela, A. (2006): "Transformaciones territoriales y valoración social del paisaje”, en Mata Olmo, R. y Tarroja Coscuela, A. (coords.), El paisaje y la gestión del territorio. Criterios paisajísticos en la ordenación del territorio y el urbanismo, Barcelona, Diputación de Barcelona y CUIMPB.

Tejedor Bielsa, J. (1999): “Propiedad, urbanismo y Estado autonómico”, en Revista de Administración Pública núm. 148.

Zoido Naranjo, F. (2000): “Estudios sobre el paisaje”, en Martínez de Pisón, I. (dir.), Madrid.

Zoido Naranjo, F. (2001): “La Convención Europea del Paisaje y su aplicación en España”, en Revista Ciudad y Territorio-Estudio Territoriales, núm. XXXIII (128). 
